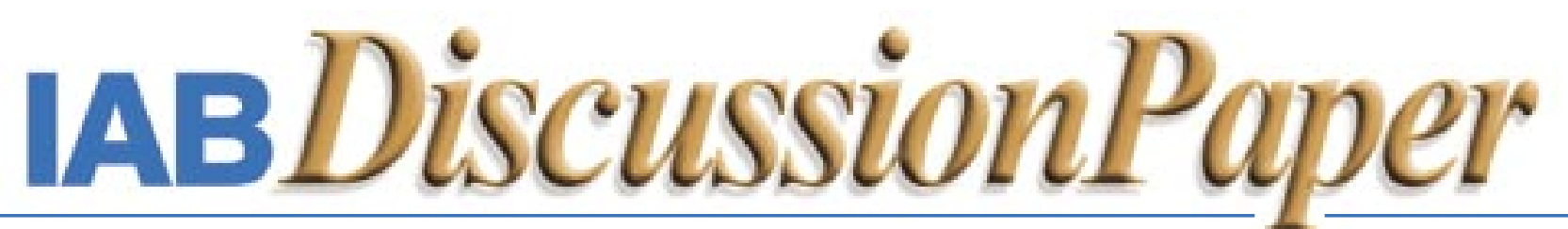

Beiträge zum wissenschaftlichen Dialog aus dem Institut für Arbeitsmarkt- und Berufsforschung

No. 10/2006

\title{
Base Period, Qualifying Period and the Equilibrium Rate of Unemployment
}

Elke J. Jahn, Thomas Wagner 


\title{
Base Period, Qualifying Period and the Equilibrium Rate of Unemployment
}

\author{
Elke J. Jahn (Institute for Employment Research - IAB, \\ University of Erlangen-Nuremberg, IZA Bonn), \\ Thomas Wagner (University of Applied Sciences, Nuremberg)
}

Auch mit seiner neuen Reihe „IAB-Discussion Paper“ will das Forschungsinstitut der Bundesagentur für Arbeit den Dialog mit der externen Wissenschaft intensivieren. Durch die rasche Verbreitung von Forschungsergebnissen über das Internet soll noch vor Drucklegung Kritik angeregt und Qualität gesichert werden.

\begin{abstract}
Also with its new series "IAB Discussion Paper" the research institute of the German Federal Employment Agency wants to intensify dialogue with external science. By the rapid spreading of research results via Internet still before printing criticism shall be stimulated and quality shall be ensured.
\end{abstract}




\section{Contents}

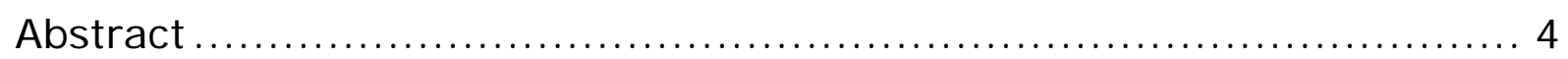

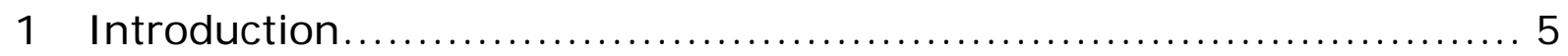

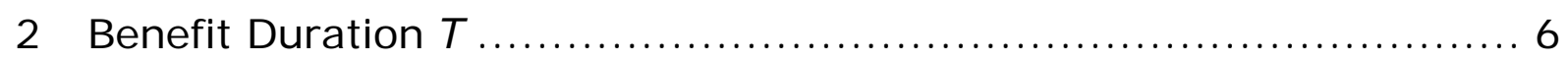

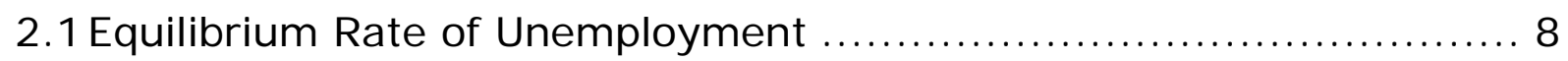

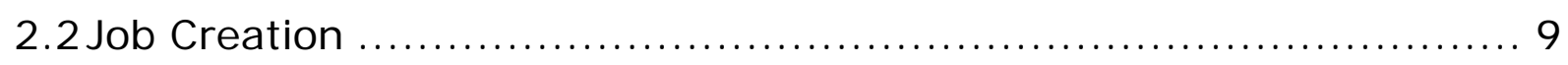

2.3 Wage Negotiation and J ob Destruction.............................. 11

2.4 Solution and Labor Market Policy .................................... 14

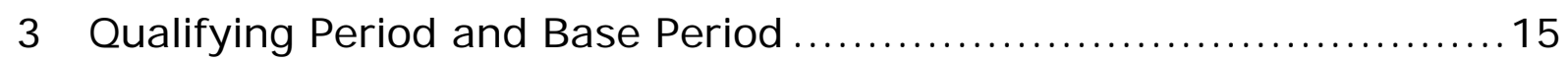

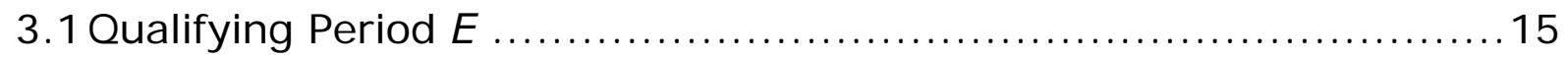

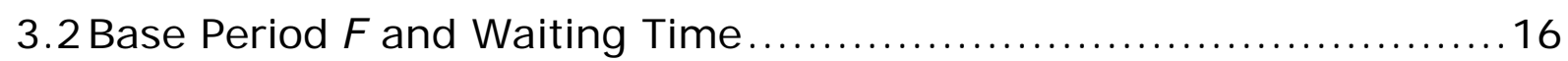

3.3 Qualifying Path and the Equilibrium Rate of Unemployment ...........19

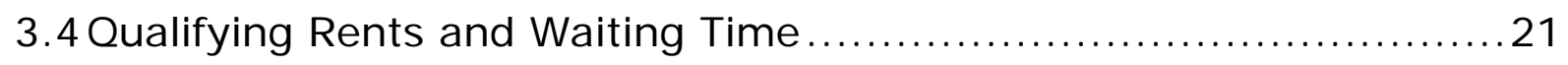

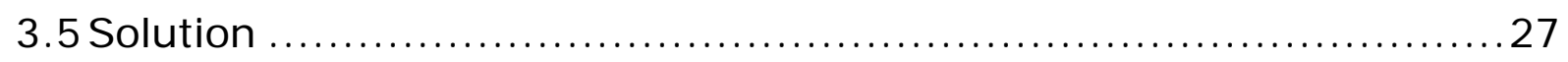

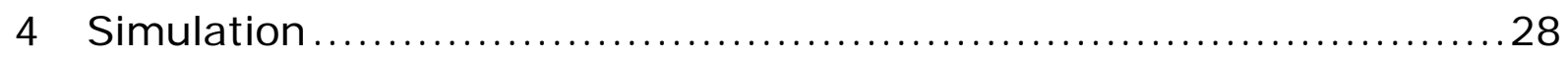

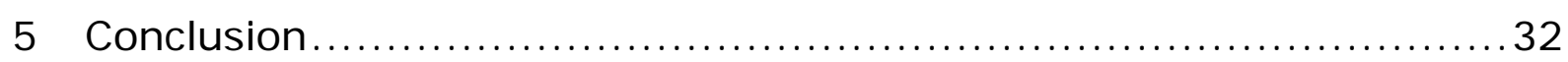

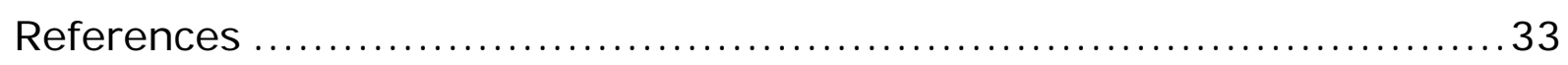

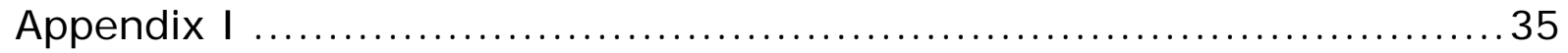

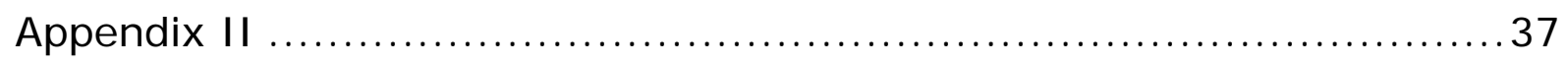

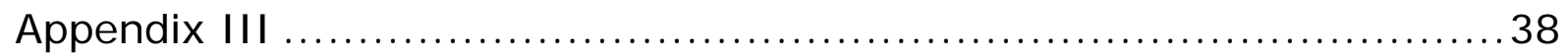

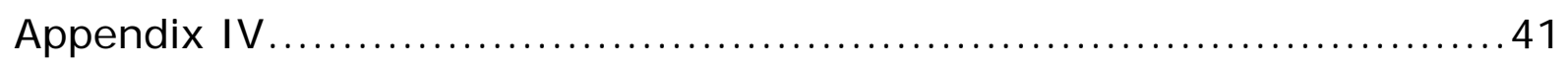




\begin{abstract}
Unemployment benefits, benefit duration, base period and qualifying period are constituent parameters of the unemployment insurance system in most OECD countries. From economic research we know that the amount and duration of unemployment benefits increase unemployment. To analyze the effects of the other two parameters we use a matching model with search frictions and show that there is a trade-off between the qualifying and the base period on the one hand and the amount and duration of the unemployment benefits on the other. A country that combines a high level of unemployment benefits with a long benefit duration can neutralize the effect on the equilibrium rate of unemployment with a long qualifying and/or a short base period.
\end{abstract}

Keywords: Matching model, unemployment insurance, base period, qualifying period, labor market policy

JEL-Code: J41, J64, J68

We are grateful to Herbert Brücker, Robert Hall, Julie L. Hotchkiss, Rüdiger Wapler and the participants of the Annual Congresses of the Royal Economic Society 2004, European Association of Labour Economists 2004, Scottish Economic Society 2005, International Conference on Policy Modeling 2005, European Economic Association 2005 and Society of Labor Economists 2006 for their valuable and helpful comments. 


\section{Introduction}

Base and qualifying period are constituent parameters of the unemployment insurance system in most of the OECD countries. A worker must complete the qualifying period within a statutory base period in order to obtain a claim for unemployment benefits (UB). The qualifying period is often described as a rule having a financing and an information function, which reduces the moral hazard of the unemployed. The longer the qualifying period, the lower the likelihood that workers will register as 'false' unemployed to capture UB and the higher the accumulated contributions to the unemployment insurance, when they once will claim benefit payments. Table 1 shows the qualifying and the base period of the US, Great Britain, Japan, and some of the Continental European countries. For example, Italy and Germany apply a rule, where a worker must have been employed at least for 12 months during the last 2 years in order to be eligible for UB. The qualifying period is much shorter in France and the Netherlands than in Germany or Italy; this is also true for the base period in the Netherlands.

Table 1: Characteristics of the unemployment insurance system in selected OECD countries $2002^{1)}$

\begin{tabular}{|l|c|c|c|}
\hline & $\begin{array}{c}\text { Qualifying Period } \\
\text { (months) }\end{array}$ & $\begin{array}{c}\text { Base Period } \\
\text { (months) }\end{array}$ & $\begin{array}{c}\text { Max. Benefit } \\
\text { Duration (months) }\end{array}$ \\
\hline Denmark & 12 & 36 & 48 \\
France & 4 & 18 & 30 \\
Germany (2006) & 12 & 24 & 12 \\
Italy & 12 & 24 & 6 \\
Japan & 6 & 12 & 10 \\
Netherlands & 6 & 9 & 18 \\
Spain & 12 & 72 & 24 \\
UK & 24 & n.a. & 6 \\
USA (2006) & 12 & 16 & 6 \\
\hline
\end{tabular}

1) for a 40 year old single worker without children, with 22-year employment career Source: OECD 2004, US Department of Labor

Of the four parameters - base period, qualifying period, UB and benefit duration - we know from economic theory (Mortensen 1977, Mortensen and Pissarides 1999, Pissarides 2000, Rogerson et. al 2005) and empirical research (Atkinson and Micklewright 1991, Layard et al. 1991, Nickell and Layard 1999, Nickell et al. 2005) that the amount and the duration of UB increase the equilibrium rate of unemployment. While the literature has 
focused on the impact of the amount and duration of UB on the unemployment rate, there seems to be neither theoretical nor empirical research on the base and the qualifying period. To analyze the effects of the two parameters, we use a Mortensen-Pissarides type (MP) matching model with search frictions (Mortensen and Pissarides 1994, Pissarides 2000) and show that there exists a trade-off between the qualifying period and the base period, on the one hand, and the amount and the duration of UB, on the other. Therefore, it is possible for a country to offer its job seekers a high level of UB with a long benefit duration, while neutralizing the effect on the equilibrium rate of unemployment with a long qualifying period and/or a short base period.

The paper is structured as follows. Section 2 introduces the MP-model with a finite benefit duration. In Section 3, we integrate the base period and the qualifying period into the modified MP-model. Section 4 presents numerical simulations. Section 5 concludes. A graphical presentation of the simulation results can be found in the Appendix I. Appendices II-IV present the proofs of the propositions.

\section{Benefit Duration T}

The time structure of the model is discrete. Job creation takes place at the beginning of a period and job destruction at the end of a period. At the beginning of a period, a continuum of applicants look for suitable vacancies. When a worker and a vacancy meet, they negotiate the employment contract and begin production. At the end of the period, the output is sold, the wage is paid and the match partners decide on whether to continue the job. Idiosyncratic shocks which are caused by shifts in product demand or by a change of the unit costs of production affect the productivity of the match. If the productivity is too low, the job is destroyed and the worker becomes unemployed. Eligible job seekers receive UB, which are paid as a flat rate at the end of a period.

The labor force is represented as a unit mass, each worker is either employed or unemployed, hence $1=e+u$, where $e$ denotes the pool of employed and $u$ the pool of unemployed. Out of the employed, $\lambda G(R) e$ lose their job at the end of a period. $\lambda G(R)$ is the endogenous separation rate, where $\lambda$ is the probability of a job-specific shock $x . G(x)$, with the support 
$0 \leq \alpha \leq x \leq 1$, is the distribution function of $x . R \geq \alpha$ is the endogenous reservation productivity and $y x$ is the real output of the job, with the maximum productivity $y>0$. Worker and firm prefer the same separation rule: If $x \geq R$, the job is continued. If $x<R$, the job is destroyed. Since $R$ is endogenous and $x$ is bounded from below, worker and firm can avoid job destruction by agreeing on the reservation productivity $R=\alpha$. The $u$ job seekers apply if they meet a vacancy. Job seekers apply at most once per period and vacancies receive no more than one application.

Unemployment incidence. J ob search takes place at the beginning of a period. J ob seekers, who lost their job at the end of the previous period and do not find a re-engagement, form the inflow $I$ of the pool of unemployed: $I \equiv(1-p) \lambda G(R) e$, where $p$ is the transition probability into employment, $0<p<1$. We call $(1-p) \lambda G(R)$ the ex-post-incidence. The unemployment incidence $\lambda G(R)$ comprises, in addition to the ex-post-incidence, job seekers who find a re-engagement immediately after losing their previous job, as $\lambda G(R)=p \lambda G(R)+(1-p) \lambda G(R)$, where $p \lambda G(R)$ is the fraction of the job-tojob transitions.

Unemployment Insurance. Workers without a job register with the unemployment insurance $[T, b]$, which has the following two properties.

(A1) [Employed Worker]. As in the MP-model each employed worker is entitled to claim UB $b>0$ if laid off. In contrast to the MP-model the benefit duration is limited to $T \geq 0$ periods.

(A2) [J ob Seekers]. $u_{T-j}$ is the pool of job seekers with a residual benefit duration of $T-j \geq 0$ periods. $j$ is the current spell of unemployment, $j=0, \ldots, T$. An additional period of unemployment raises the current spell from $j$ to $j+1$ periods, reduces the counter of the residual claims to $T-(j+1) \geq 0$ and places the unemployed into pool $u_{T-(j+1)}$. Job seekers, who have not found a job $T$ or more periods after losing their previous employment, lose their eligibility to UB and form the job seeker pool $u_{0}$. 


\subsection{Equilibrium Rate of Unemployment}

Job seekers from the pool $u_{T}$, who lost their job at the end of the previous period, are entitled to UB for $T$ periods. From (A1) and (A2) it follows that the inflow $I$ is identical to the pool $u_{T}$, so that $u_{T}=(1-p) \lambda G(R) e$. Those job seekers from $u_{T}$, who still have no job at the succeeding period, form by (A2) the pool $u_{T-1}$. For the pool of job seekers with a counter of residual claims equal to $T-j$, we have in the steady state

$$
u_{T-j}=(1-p)^{j+1} \lambda G(R) e, j=0, \ldots, T-1 .
$$

Since $p<1, u_{T-j}$ strictly decreases with an increasing spell length $j$.

Of the unemployed in the pool $u_{0}, p u_{0}$ find a job. Thus we have in the steady state: $p u_{0}=(1-p)^{T+1} \lambda G(R) e$. From this steady state condition, we can derive $u_{0}$

$$
u_{0}=\frac{(1-p)^{T+1}}{p} \lambda G(R) e
$$

Finally, we obtain the aggregate pool of job seekers $u$ from

$$
u=\sum_{j=0}^{T} u_{T-j} .
$$

Matching function. The labor market is a search market. $m(u, v)$ represents the matching technology of the market, where $m$ is the number of jobs filled with an input of $u$ job seekers and $v$ vacancies. The matching function is linear homogenous, concave and monotone in both arguments. For a given vacancy, $q(\theta) \equiv m(1 / \theta, 1)=m(u, v) / v$ is the probability of an application, where the ratio of vacancies to job seekers, $\theta=v / u$, is the tightness of the labor market. For a given job seeker, $p(\theta)=\theta q(\theta)$ is the transition probability into employment. For convenience, we will write $q=q(\theta)$ and $p=p(\theta)$.

Inserting ( 1 ) and (2) into (3) gives the equilibrium rate of unemployment as a function of the tightness and the reservation productivity

$$
u(\theta, R)=\frac{[1-p(\theta)] \lambda G(R)}{[1-p(\theta)] \lambda G(R)+p(\theta)} .
$$


The parameters of the unemployment insurance $T$ and $b$ do not affect $u$ directly, but rather through the ex-post-incidence, $(1-p) \lambda G(R)$ and the duration of unemployment, $1 / p$.

\subsection{J ob Creation}

Filled Jobs. An employment contract $\left[w_{T-j}, w(x), R\right]$ has three components. $W_{T-j}$ is the outside wage the worker earns in the first period. The outside wage depends on the residual claims of the job seeker. If the negotiations fail, the worker receives UB $b$ for up to another $T-j$ periods, $j=0, \ldots, T$.

The second component of the contract is the match specific inside wage with the wage function $w:[R, 1] \rightarrow \Re$. At the end of a period, the succeeding periods' productivity $y x$ is revealed to the match. If $x \in[R, 1]$, the match is continued and the worker gets paid $w(x) .{ }^{1}$ The third component of the contract shows the reservation productivity $R$ at which the job will be destroyed.

Continuation periods. Job-specific shocks hit a match with probability $\lambda \geq 0$. A job will be affected by no more than one shock per period, where shocks are iid.

Let $\Pi(x)$ be the present value of a filled job after the manifestation of $x \in[\alpha, 1]$. Worker and firm are both interested in continuing the match as long as $\Pi(x) \geq 0$ and agree on job destruction as soon as $\Pi(x)<0$, as will be shown below. Since $\Pi(x)$ is a continuously increasing function of $x$, a reservation threshold $R$ exists, for which

$$
\Pi(R)=0 .
$$

Only jobs with $x \geq R$ will be continued.

1 Mortensen/Pissarides (1999) and Pissarides (2000) present a discussion of objections against the plausibility of this assumption and the two-tier wage structure which results from the possibility of renegotiation. 
We assume that the firm sells the output $y x$ at the end of the period at the same time as it pays the wage $w(x)$. Then the steady state equation for the present value $\Pi(x)$ is

$$
\Pi(x)=\rho\left\{y x-w(x)+\lambda \int_{R}^{1} \Pi(h) d G(h)+(1-\lambda) \Pi(x)\right\} .
$$

Flow and stock variables are discounted at the factor $\rho$, where $0<\rho=1 /(1+r)<1$ with the real interest rate $r>0$. The job is hit by a shock with probability $\lambda$ and changes into state $h$. If $R \leq h \leq 1$, the match is continued and the continuation value becomes $\Pi(h)$. The match specific productivity does not change with probability $1-\lambda$.

A worker employed at the productivity $x$ earns the wage $w(x)$, and his human capital has the present value $W(x)$. The asset pricing equation for the worker is

$$
W(x)=\rho\left\{W(x)+\lambda\left[\int_{R}^{1} W(h) d G(h)+G(R) U_{T}\right]+(1-\lambda) W(x)\right\} .
$$

With probability $\lambda$ a shock arrives and the match draws the productivity $h$. If $h \geq R$, the value of the worker is $W(h)$ and the match continues. If, on the other hand, $h<R$, which happens with probability $G(R)$, the job is destroyed, the worker becomes unemployed and the value of his human capital is $U_{T}$ (see Equation (13)).

Initial period. Firms choose the initial productivity $x=1$ when they set up a match and negotiate the outside wage. If the firm meets a worker with a current spell of unemployment of length $j$, then the market value $\Pi_{T-j}$ of the newly filled job is

$$
\Pi_{T-j}=\Pi(1)+\rho\left[w(1)-w_{T-j}\right], j=0, \ldots, T,
$$

where $w_{T-j}$ is the outside wage, $\Pi(1)$ is the continuation value (6) and $w(1)$ is the inside wage of a job with the productivity $x=1$. 
The market value of an entrant with a current spell of unemployment of length $j$ is with respect of the asset Equation (7) and the outside wage $w_{T-j}$ :

$$
W_{T-j}=W(1)+\rho\left[W_{T-j}-w(1)\right], j=0, \ldots, T .
$$

Job creation. Entrance into the labor market is free for all vacancies, but open only at the beginning of a period. The flow of vacancies persists until the present value of a vacancy is zero. Considering this infinitely elastic supply of vacancies, the job creation condition is

$$
0=-k+q \sum_{j=0}^{T} \mu_{T-j} \Pi_{T-j},
$$

where $k$ denotes the flow costs for advertising a vacancy, $q$ is the probability of meeting a job seeker, $\mu_{T-j}$ the conditional probability that the applicant will have a current spell of unemployment of length $j$ and $\Pi_{T-j}$ the value of the newly filled job according to Equation (8).

All job seekers search for jobs with the same intensity. Therefore, $\mu_{T-j}=u_{T-j} / u$ denotes the probability with which a vacancy will meet a job seeker with a current spell of unemployment of length $j$. Taking into account the pool Equations (1), (2) and (4), the following relationship holds

$$
\mu_{T-j}=\left\{\begin{array}{l}
p(1-p)^{j}, j=0, \ldots, T-1 \\
(1-p)^{T}, j=T
\end{array}\right.
$$

\subsection{Wage Negotiation and J ob Destruction}

Value of unemployment. Unemployed who are not eligible for UB have the value $U_{0}$, where in the steady state

$$
U_{0}=p W_{0}+(1-p) \rho\left(z+U_{0}\right) .
$$

The job seeker finds a job with probability $p$, and his human capital takes on the initial value $W_{0}$ (see Equation (9)). If he is not matched, the utility from leisure is equal to $z$.

The human capital of a job seeker with a current spell of unemployment of length $j$ has the value $U_{T-j}$. In the steady state, the first-order linear inhomogeneous difference equation for $U_{T-j}$ is

$$
U_{T-j}=p W_{T-j}+(1-p) \rho\left[z+b+U_{T-(j+1)}\right], j=0, \ldots, T-1 .
$$


The human capital of the outsider, who meets a vacancy, has the value $W_{T-j}$ (see Equation (9)). If the job seeker does not meet a vacancy, he receives the UB $b$ in addition to the utility of leisure $z$, the counter of the current spell of unemployment increases to $j+1$ and his human capital takes on the value $U_{T-(j+1)}$.

Wage negotiations. J ob search takes time and causes search costs. Therefore, as a consequence of search frictions, each match generates a positive monopoly rent, which is distributed between the match partners through the wage. The sharing rule is obtained according to the generalized Nash solution to a bargaining problem, with $\beta \in(0,1)$ denoting the bargaining strength of the job seeker.

Taking into account the idiosyncratic productivity shock $x \in[R, 1]$, the reservation utility of the insider $U_{T}$, and the fact that the asset price of a vacancy is equal to zero in the steady state, the sharing rule implemented by the negotiations with an insider is

$$
W(x)-U_{T}=\frac{\beta}{1-\beta} \Pi(x) .
$$

$W(x)-U_{T}$ denotes the worker's contribution and $\Pi(x)$ the firm's contribution to the total surplus of the job.

The job rent of a match with an outsider, who has a current spell of unemployment of length $j$, will be shared according to the following rule

$$
W_{T-j}-U_{T-j}=\frac{\beta}{1-\beta} \Pi_{T-j}, j=0, \ldots, T,
$$

where the asset Equations (8), (9), (12) and (13) give the initial values of the outsider, $W_{T-j}$, the newly filled job, $\Pi_{T-j}$, and the value of the unemployed at the time of wage negotiations, $U_{T_{-j}}$. Proves of the following lemmas 1. - 3. can be found in Appendix II.

Lemma 1 [Bargained Wages]. In view of the reservation income $r U_{T}$ of the insider and the value $U_{T-j}$ of the job seekers with a current spell of unemployment of length $j$, the agents negotiate the following inside and outside wages.

(i) [Inside Wage] The bargained inside wage at a match specific productivity $x \in[R, 1]$ is

$$
w(x)=r U_{T}+\beta\left(y x-r U_{T}\right) .
$$


(ii) [ Outside Wage] An outsider with a current spell of unemployment of length $j$, who produces in the first period with productivity $x=1$, earns the wage

$$
w_{T-j}=w(1)-(1-\beta)\left(U_{T}-U_{T-j}\right) \rho^{-1}, j=0, \ldots, T,
$$

where $w(1)$ is the inside wage (16) for $x=1$, and $\rho^{-1}=1+r$.

By Equation (16) the inside wage equals the reservation income of the worker plus a share of the current match rent that depends on his bargaining strength $\beta$.

Should an outsider with a current spell of unemployment of length $j$ find a job, then the guarantee value of his human capital increases by the amount of the differential rent $U_{T}-U_{T-j}$. As the wage Equation (17) illustrates, the firm which places the outsider under contract takes the fraction $1-\beta$ of this rent.

The job destruction condition can be derived by evaluating the asset Equation (6) at the reservation threshold $x=R$ to obtain:

Lemma 2 (i) [Filled J obs]. The continuation value of a filled job producing with the idiosyncratic productivity $x \in[R, 1]$ is

$$
\Pi(x)=(1-\beta) y \frac{x-R}{\lambda+r} .
$$

(ii) [J ob Destruction Rule]. The job destruction rule is

$$
R=\frac{r U_{T}}{y}-\frac{\lambda}{(1-\beta) y} \int_{R}^{1} \Pi(h) d G(h) .
$$

As the job destruction condition (19) illustrates, the current reservation output of a match is lower than its permanent reservation income. Since the firm can destroy the job at no charge (free disposal) and the supply of vacancies is infinitely elastic, the reservation income of the match is identical with the reservation wage of the worker, $r U_{T}$. Therefore, when the job produces the reservation output $y R$, the match suffers a current loss equal to the integral expression in (19). The option value of the filled job is the reason why the match partners are willing to accept this loss.

In order to close the model, we still have to determine the reservation wage of the different types of unemployed. The unemployment insurance $[T, b]$ creates a discrete distribution with $T+1$ types in the pool of job seekers. The job seekers differ with respect to their residual entitlement to UB and in turn in their reservation utility and the outside wages they are 
able to demand when matched to a vacancy. Given the distribution of the market values of the $T+1$ job seeker types, we finally can derive the distribution of the initial values of the filled jobs.

Lemma 3 (i) [Reservation Wage]. From the asset equations for the job seekers, the sharing rules and the equations for the initial values, we obtain the distribution of the reservation wage of the $T+1$ job seeker types with

$$
\begin{aligned}
& r U_{T-j}=z+\left(1-d^{T-j}\right) b+\frac{\beta p}{(1-\beta)(1-p)}\left[\Pi(1)+(1-\beta)\left(U_{T}-U_{T-j}\right)\right] \rho^{-1}, j=0, \ldots, T \\
& \text { where } d(\theta) \equiv \frac{[1-p(\theta)] \rho}{1-(1-\beta) p(\theta)} \in(0,1) .
\end{aligned}
$$

(ii) [ I nitial Values]. The distribution of the initial values of occupied jobs is obtained from

$$
\Pi_{T-j}=\Pi(1)+(1-\beta)\left(U_{T}-U_{T-j}\right), j=0, \ldots, T .
$$

As (20) and (21) show, while, ceteris paribus, the reservation wage of a job seeker with a current spell of unemployment of length $j$ decreases, the value of a job filled with an outsider with the same current spell increases monotonically with $j$. As a result, the unemployed without benefit entitlement from pool $u_{0}$ have the lowest market value of all job seekers, while correspondingly jobs filled by unemployed workers without entitlement have the highest market value of all newly formed jobs.

\subsection{Solution and Labor Market Policy}

The equilibrium of the search model consists of solutions $\left[\Pi(1), U_{T-j}, \theta, R, u\right], j=0, \ldots, T$, to the Equations (10), (18) - (20) and the equilibrium unemployment rate (4). Like the standard MP-model the enhanced model has two independent endogenous variables, the reservation productivity $R$ and the labor market tightness $\theta$. To solve for these two unknowns we can use the job destruction condition (19), which is in view of the income Equation (20) and the asset Equation (18) an equation in $[\theta, R]$. The second key equation of the model is the job creation condition (10), which depends after eliminating the transition probabilities with (11) and the initial values of a filled job with the asset Equations $(21)$ on $[\theta, R]$. The asset Equations (20) and (21) make use of the 'entitlement rents' $U_{T}-U_{T-j}, j=1, \ldots, T$. The entitlement rents result from 'institutional frictions', which are created by the public unemployment insurance system. 
All the $T$ entitlement rents are functions of the labor market tightness, as follows from the asset Equations (20).

Labor Market Policy. The following proposition characterizes the impact of the policy parameter $T$. An increase in the benefit duration $T$ raises the fraction of job seekers with a long residual duration of benefit entitlement. Their reservation wage increases and, consequently, the outside wages they demand increase too. The initial values of the newly established firms fall and the supply of vacancies declines. In turn, the tightness of the labor market decreases and the duration of unemployment $1 / p$ rises. In addition, the ex-post-incidence $(1-p) \lambda G(R)$ increases. The rising duration of unemployment and the higher ex-post-incidence are each sufficient to raise the equilibrium rate of unemployment. The Figures $3 a-c$ in Appendix I for $E=1$ illustrate the argument.

\section{Qualifying Period and Base Period}

In the unemployment insurance $[E, F, T, b]$ with qualifying period $E \geq 2$ and base period $F \geq E$, workers who lose their job before completing the qualifying period have no claim to UB. In order to model the insurance, we introduce the following five assumptions (A1) - (A5), where (A1) - (A4) deal with the qualifying period $E$ and (A5) describes the role of the base period $F$.

\subsection{Qualifying Period E}

(A1) [Completed Qualifying Period]. The qualifying period of a worker is completed, if he was employed for at least $E \geq 2$ periods during the base period $F$. An unemployed person with a completed qualifying period is entitled to $T$ payments of the UB $b$.

(A2) [Transferability]. Residual claims for UB from earlier unemployment spells are lost. Qualifying points are intertemporally transferable.

(A3) [Employed worker]. Each employed worker is characterized by a tupel $[E-i, C]$. The counter $E-i \geq 0$ shows the number of currently accumulated qualifying points of the worker; $i$ denotes the number of uncompleted qualifying time periods, with $i=0, \ldots, E-1$ and $C \in\{0, T\}$ is a binary variable and either equal to $T$ or zero - depending on whether the 
qualifying period is completed and the worker is entitled to UB or not. During an uncompleted qualifying period, an additional period of employment raises the counter of the qualifying points from $E-i$ to $E-(i-1) \leq E$.

(A4) [Job Seekers]. Each job seeker is characterized by a tupel $[E-i, T-j]$ : The counter $E-i \geq 0$ shows the number of currently accumulated qualifying points and $T-j \geq 0$ the residual benefit duration, where $j=0, \ldots, T$. An additional period of unemployment of a job seeker, who still owns residual benefit claims, raises the length of the current spell of unemployment from $j$ to $j+1$ and reduces the counter for the residual benefit duration from $T-j$ to $T-(j+1) \geq 0$.

\subsection{Base Period F and Waiting Time}

With given UB $b$ the reservation utility of an applicant, his initial wage as well as the initial market value of a filled job depend on the following three attributes of the insurance system $[E, F, T, b]$ : First, the accumulated qualifying points $E-i$; second, the distribution of the $E-i$ employment periods over the base period $F$; and third, the counter of the residual benefit duration $T-j$. The longer the residual benefit duration, or the higher the number of accumulated qualifying points, or the sooner the job seeker will complete the qualifying period (i.e. the shorter his waiting time), the higher his wage demand will be during the initial contract negotiations.

The length of the waiting time of a job seeker with characteristics $[E-i, T-j]$ is the time that passes until his next benefit entitlement begins. The waiting time is a random variable, which depends on the accumulated qualifying points $E-i$ and on the distribution of the $E-i$ employment periods over the base period $F$, as we will explain in more detail in the following sections. The longer $F$ is, the greater, ceteris paribus, is the number of different employment careers with exactly $E-i$ qualifying points and the greater is the range of the distribution of different waiting 
times of otherwise identical job seekers. ${ }^{2}$ There are two cases to distinguish.

First, if $F=E$, there is exactly one employment career which meets the qualification requirement: Only those workers who were continuously employed for at least $E$ periods are eligible to UB. Second, if $F>E$, then the number of different employment careers with a current counter of $E-i \geq 0$ qualifying points is possibly very large, as is indicated by the following simple example. Let $A$ and $B$ be two job seekers with identical qualifying counters $E-i \geq 0$. Assume that both remain unemployed in the next period and, moreover, that $A$ was employed $F$ periods ago, while $B$ was not. Then $A$ loses one qualifying point and faces the counter $E-(i+1)$ at the end of the current period, whereas $B$ still owns $E-i$ points. Even though both workers have accumulated an additional unemployment period at the end of the current period, the 'bifurcation' arises, because the unemployed $A$ replaces a period of employment at the beginning of the current base period with the current unemployment period, so that his qualifying counter decreases by one; whereas $\mathrm{B}$, on the other hand, replaces an unemployment period at the beginning of the current base period with the current unemployment period, so that his qualifying counter remains constant. Consequently, the expected waiting time of $A$ is at least one period longer than the waiting time of $\mathrm{B}$.

An investor offering a vacancy knows just as little ex ante about the applicants specific employment careers as about their accumulated qualifying points or their residual benefit claims. Yet the ex post value of the job and, consequently, his decision to offer a vacancy depends on these variables and on his expectations concerning these characteristics of an applicant. In order to provide a simple model of the investor's decision, we introduce assumption (A5) below, which assures that the initial value of a filled job, $\Pi_{E-i T-j}$, will indeed only depend on the characteristics $[E-i, T-j]$ of the applicant and not on the distribution of the $E-i$ em-

2 In total, there are $\left(\begin{array}{c}F \\ E-i\end{array}\right)$ employment careers with $E-i$ qualifying points in the base period $F, i=0, \ldots, E$. If, for example, - as in Germany - the base period comprises $F=24$ months and the qualifying period $E=12$ months, then there are $\left(\begin{array}{l}F \\ E\end{array}\right)=2,7 * 10^{6}$ possible employment careers with a completed qualifying period. 
ployment periods over the base period $F$. The risk-neutral investor then needs only to estimate the probability $\mu_{E-i T-j}$ of meeting a type $[E-i, T-j]$ applicant.

We model the effect of the applicants employment careers and the above mentioned bifurcation on the decision of the investors to offer vacancies using the following Markov process. Let $u_{E-i T-j}$ denote the pool of job seekers with $E-i$ qualifying points and $T-j$ residual benefit periods.

(A5) [Employment Career]. The unemployed from $u_{E-i T-j}$, who have found no job, make either a transition into the pool $u_{E-i T-(j+1)}$ (like the job seeker $B$ in the above example) or into the pool $u_{E-(i+1) T-(j+1)}$ (like the job seeker $A$ in the above example), where the first transition occurs with the probability $\gamma \in[0,1)$ and the second with the probability $1-\gamma \in(0,1]$.

At the micro level, there exists no correlate of the transition probability $\gamma$. At the macro level in contrast, the policy parameter $\gamma$ has quite the same effect as the distribution of the employment periods $E-i$ over the base period $F$. First, if $F=E$, this case corresponds to a transition probability of $\gamma=0$, as there is only one employment career which meets the qualification requirement. In the second case $F>E$. The longer the base period $F$ ceteris paribus the higher is the fraction of agents in the inflow to the aggregate pool of unemployed $u$, who can claim UB. An increase in the transition probability $\gamma$ has obviously the same effect on the mix of types in the inflow to $u$ as an extension of the base period $F$. The reason is that on the macro level, $\gamma$ determines the fraction of the job seekers from the aggregate pool $u_{E-i} \equiv \sum_{j=1}^{T} u_{E-i T-j}, i=0, \ldots, E$, whose qualifying counters do not decrease despite the advancing calendar time and who therefore search for a job in the following period with $E-i$ qualifying points again. ${ }^{3}$ On the other hand, for the fraction $1-\gamma$ of the unemployed from pool

3 The effects of the parameters of the labour market policy $[E, \gamma, T, b]$ on the equilibrium unemployment rate $u$ do not depend on whether the qualifying period $E$ is shorter or longer than the benefit duration $T$. For the sake of brevity, we present the model equations for the case $E \leq T$, which most of the OECD (2004) countries follow. The simulations and results in Section 4 of the paper, however, also take into account the case $E \geq T+1$. 
$u_{E-i}$, both the counter of the residual claims and the qualifying counter decrease by one and their reservation income reduces correspondingly. Third - just as in the case $F \rightarrow \infty-$, if $\gamma \rightarrow 1$, the fraction of the employed workers with a completed qualifying period approaches unity irrespective of the length of the qualifying period $E$.

\subsection{Qualifying Path and the Equilibrium Rate of Unem- ployment}

The unemployment insurance $[E, \gamma, T, b]$ with qualifying period $E$, base period $\gamma$ and benefit duration $T$ creates a discrete distribution of $E$ types among the pool of employed workers: Employed workers differ in the qualifying counter $E-i, i=0, \ldots, E-1$. In the following, $e_{E-i}$ denotes the pool of workers with $E-i$ qualifying points. Among the $u$ unemployed, the unemployment insurance likewise creates a discrete distribution of types, who differ with respect to the qualifying points $E-i$, where $i=0, \ldots, E-1$, and the residual benefit duration $T-j$, where $j=i, \ldots, T$ by assumption (A5) and $T \geq E .^{4}$

Since the time of the model is discrete, every employed worker owns at least one qualifying point. Job seekers from the pool $u_{0}=\sum_{j=E}^{T} u_{0 T-j}$, who do not possess qualifying points, begin their employment career in the pool $e_{1}$ and make a transition to the pool $e_{2}$, if $x \geq R_{2}$ at the end of the first period of the current employment spell. ${ }^{5} R_{2}$ is the reservation productivity for the transition from the pool $e_{1}$ to pool $e_{2}$, see Figure 1 . Consider a filled job with $E-i, i=1, \ldots, E-1$, qualifying points. At the end of the period the firm has to decide whether to continue the job or not. Given $x \in[\alpha, 1]$, the match is continued if $x \geq R_{E-(i-1)}$ and the worker makes

4 If $E \leq T$, there are $\sum_{k=1}^{E+1}(T-E+k)=(E+1)(T+1)-E(E+1) / 2$ types of job seeker; if $E \geq T+1$, the number of job seeker types amounts to $\sum_{k=0}^{T}(T+1-k)+(E-T)=T(T+1) / 2+(E+1)$. The steady state equations for the employees $e_{E-i}$ and job seekers $u_{E-i T-j}$ are developed further in Appendix IV.

5 Whether the creation of vacancies is profitable depends in particular on the reservation productivity $R_{1}$. For profitability $R_{1} \leq 1$ is a necessary condition because the firms choose the initial productivity at $x=1$. 
a transition to the pool $e_{E-(i-1)}$. Otherwise the match dissolves, the job becomes vacant and the worker unemployed - without claim to UB. Match partners from the pool $e_{E-1}$ close to the completion of the qualifying period decide to continue and make a transition to pool $e_{E}$, if $x \geq R_{E}$. The pool $e_{E}$ comprises exclusively jobs with a completed qualifying period. A job from $e_{E}$ is continued, if $x \geq R_{E+1}$. Otherwise, it is destroyed, and the worker becomes unemployed - with claim to UB. $R_{E+1}$ is the reservation productivity of the jobs with a completed qualifying period.

We call the path of the reservation productivities $\Psi_{E}=\left[R_{2}, \ldots, R_{E}\right], E \geq 2$, the qualifying path: Every worker must - possibly interrupted by unemployment spells - pass through the qualifying path $\Psi_{E}$ before his qualifying period is completed and he is entitled to UB.

Figure 1: Qualifying path

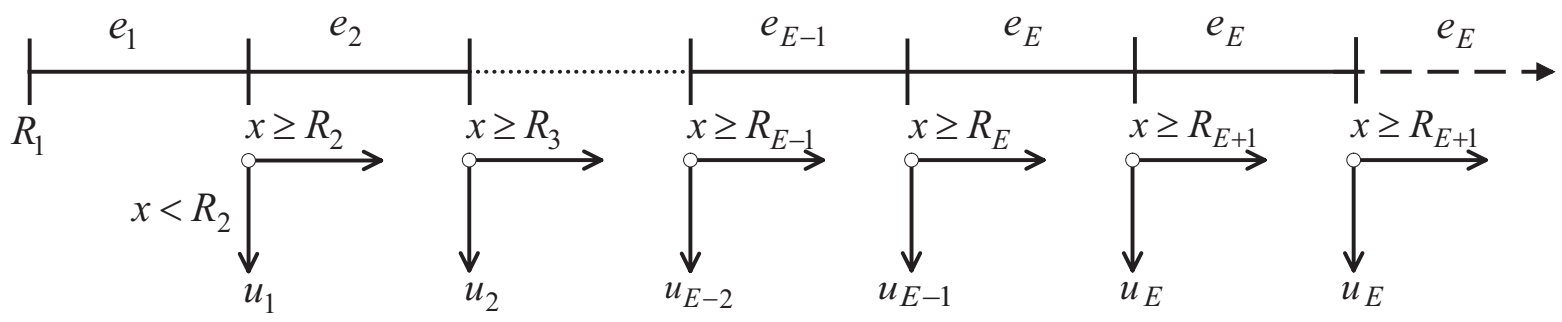

Out of the $e_{E-i}$ employed workers with the qualifying counter $E-i$, $\lambda G\left(R_{E-(i-1)}\right) e_{E-i}$ lose their job at the end of the period. In the ensuing matching at the beginning of the following period, $(1-p) \lambda G\left(R_{E-(i-1)}\right) e_{E-i}$ do not meet a vacancy and form the inflow to the pool of unemployed $u_{E-i}$; $(1-p) \lambda G\left(R_{E-(i-1)}\right)$ is the ex-post-incidence among the workers with the qualifying counter $E-i$. In the steady state, entries to the unemployment pool $u$ are equal to exits, so that $(1-p) \sum_{i=0}^{i=E-1} \lambda G\left(R_{E-(i-1)}\right) e_{E-i}=p u$. If we divide both sides of the steady state condition by $e$ and take into account that $e=1-u$, we obtain the equilibrium unemployment rate

$$
u\left(\theta, \Psi_{E}, R_{E+1}\right)=\frac{[1-p(\theta)] \sum_{i=0}^{E-1} \lambda G\left(R_{E-(i-1)}\right) \varepsilon_{E-i}}{[1-p(\theta)] \sum_{i=0}^{E-1} \lambda G\left(R_{E-(i-1)}\right) \varepsilon_{E-i}+p(\theta)},
$$

where $\varepsilon_{E-i}=\varepsilon_{E-i}\left(\theta, \Psi_{E}, R_{E+1}\right)$, with $\varepsilon_{E-i}=e_{E-i} / e, i=0, \ldots, E-1$, is the fraction of the employed workers with the qualifying counter $E-i$, hence 
$\sum_{i=0}^{E-1} \varepsilon_{E-i}=1$. As Lemma $A 3$ in the Appendix IV shows, the shares $\varepsilon_{E-i}$ and therefore the unemployment rate (22) are functions of the tightness of the labor market $\theta$, the qualifying path $\Psi_{E}=\left[R_{2}, \ldots, R_{E}\right]$ and the reservation productivity $R_{E+1}$ of the jobs with a completed qualifying period.

The equilibrium unemployment rate (22) - similarly to the steady state rate (4) of the unemployment insurance $[T, b]$ - depends on, first, the weighted average of the ex-post-incidences, $[1-p(\theta)] \sum_{i=0}^{E-1} \lambda G\left(R_{E-(i-1)}\right) \varepsilon_{E-i}$, and second, the duration of job search, $1 / p(\theta)$.

\subsection{Qualifying Rents and Waiting Time}

First, we deal with the asset equations of the filled jobs and the employed workers in the continuation periods of a match, then we focus on the job creation condition, the wage negotiation, the qualifying rents and finally the waiting time. ${ }^{6}$

Continuation periods. The value of a filled job with a completed qualifying period is derived from the asset Equation (6) and the value of the worker from Equation (7). For convenience, we repeat the equations below. The market value of a filled job with a completed qualifying period is

$$
\Pi_{E+1}(x)=\rho\left\{y x-w_{E+1}(x)+\lambda \int_{R_{E+1}}^{1} \Pi_{E+1}(h) d G(h)+(1-\lambda) \Pi_{E+1}(x)\right\} .
$$

The present value of a worker with a completed qualifying period is

$$
W_{E+1}(x)=\rho\left\{W_{E+1}(x)+\lambda\left[\int_{R_{E+1}}^{1} W_{E+1}(h) d G(h)+G\left(R_{E+1}\right) U_{E T}\right]+(1-\lambda) W_{E+1}(x)\right\},
$$

where $w_{E+1}:\left[R_{E+1}, 1\right] \rightarrow \Re$ is the function of the inside wage and $U_{E T}$ is the value of a job seeker whose qualifying period and benefit entitlement are complete (see Equation (A8), Appendix III). Firm and worker with a completed qualifying period share the match rent according to the rule (14).

6 The initial value of a newly filled job, the value of an outsider, who accepts a job, and the sharing rule that job seekers and vacancies use in their first contract negotiation as well as the asset equations for the value of the unemployed are developed in Appendix III. The asset equations (A6) and (A7) determine the initial values of the jobs and the workers, the value of the unemployed human capital is represented in the equation (A8). 
The continuation value of a job with $E-i$ qualifying points, $i=0, \ldots, E-1$, and the productivity $x \in\left[R_{E-i}, 1\right]$ is given by

$$
\Pi_{E-i}(x)=\rho\left\{y x-w_{E-i}(x)+\lambda \int_{R_{E-(i-1)}}^{1} \Pi_{E-(i-1)}(h) d G(h)+(1-\lambda) \max \left\{0, \Pi_{E-(i-1)}(x)\right\}\right\} .
$$

The firm chooses the reservation productivity $R_{E-(i-1)}$, on which the transition to the pool $e_{E-(i-1)}$ depends. If the match is hit by a shock and draws the productivity $h \geq R_{E-(i-1)}$, the match is continued, otherwise it is destroyed. If no shock arrives, firm and worker must still decide whether to proceed. The reason is that if the match continues, the worker makes a transition to the pool $e_{E-(i-1)}$, so the value of the filled job in the continuation period is $\Pi_{E-(i-1)}(x)$. Since the profit maximizing firm is free to destroy the job at no charge, it decides for the alternative $\max \left\{0, \Pi_{E-(i-1)}(x)\right\}$. The worker also prefers continuation only if $\Pi_{E-(i-1)}(x) \geq 0$, as is shown below.

The value of a worker with the qualifying counter $E-i, i=0, \ldots, E-1$ is given by

$$
W_{E-i}(x)=\left\{\begin{array}{c}
\rho\left\{W_{E}(x)+\lambda\left[\int_{R_{E+1}}^{1} W_{E+1}(h) d G(h)+G\left(R_{E+1}\right) U_{E T}\right]+\right. \\
\rho\left\{W_{E-i}(x)+\lambda\left[\int_{R_{E-(i-1)}}^{1} W_{E-(i-1)}(h) d G(h)+G\left(R_{E-(i-1)}\right) U_{E-i 0}\right]+\right. \\
\left.(1-\lambda) \max \left\{U_{E-i 0}, W_{E-(i-1)}(x)\right\}\right\}, i=1, \ldots, E-1
\end{array}\right.
$$

If the job is hit by a shock and draws $h<R_{E-(i-1)}$, it is destroyed and the worker with the qualifying counter $E-i$ becomes unemployed. In the case $i=0$, the unemployed who is entitled to UB has the value $U_{E T}$; in the case $i=1, \ldots, E-1$, the worker's qualifying period is not yet completed and his value is $U_{E-i 0}$. If no shock occurs, the worker chooses the alternative $\max \left\{U_{E-i 0}, W_{E-(i-1)}(x)\right\}$. If $W_{E-(i-1)}(x) \geq U_{E-i 0}$ - or $W_{E+1}(x) \geq U_{E T}$, in the case $i=0$ - he decides to continue the match, otherwise he leaves the firm 
and makes a transition to the pool of unemployed. As the insiders share the rent of the job according to the rule

$$
W_{E-i}(x)-U_{E-(i+1) 0}=\frac{\beta}{1-\beta} \Pi_{E-i}(x), i=0, \ldots, E-1,
$$

$W_{E-(i-1)}(x) \geq U_{E-i 0}$ applies if and only if $\Pi_{E-(i-1)}(x) \geq 0$. The sharing rule (27) takes into account that the worker $[E-i, 0]$ makes a transition to $e_{E-(i-1)}$ if the wage negotiations succeed. If the bargaining fails, the worker becomes unemployed with a qualifying counter equal to $E-i$ without entitlement to benefits. In this case his value is $U_{E-i 0}$.

Job creation. Out of the $u$ job seekers, there are $u_{E-i T-j}$ with $E-i$ qualifying points and a current spell of unemployment of length $j$. Since all job seekers look for jobs with the same search intensity, for a given vacancy $\mu_{E-i T-j}=u_{E-i T-j} / u$ is the conditional probability of an application from a job seeker from $u_{E-i T-j}$. The probabilities $\mu_{E-i T-j}$ - developed in Lemma A4, Appendix IV - are functions of the tightness $\theta$, the base period $\gamma$, the qualifying path $\Psi_{E}=\left[R_{2}, \ldots, R_{E}\right]$ and the reservation productivity $R_{E+1}$ for jobs with a completed qualification. The expected market value of a newly filled job is $\sum \mu_{E-i T-j} \Pi_{E-i T-j}$. Access to the labor market is free, so that the following job creation condition applies in the steady state, given the search costs $k$ and the probability $q$ of an application:

$$
0=-k+q \sum_{i=0}^{E} \sum_{j=i}^{T} \mu_{E-i T-j} \Pi_{E-i T-j} .
$$

The agents negotiate the following inside and outside wages.

Lemma 4 [Bargained Wages]. (i) The bargained inside wage of a worker with a completed qualifying period at a match specific productivity $x \in[\alpha, 1]$ is

$$
w_{E+1}(x)=r U_{E T}+\beta\left(y x-r U_{E T}\right) \text {. }
$$

The inside wage of a worker with the counter $E-i$ and the job specific productivity $x \in[\alpha, 1]$ is:

(30) $w_{E-i}(x)=\left\{\begin{array}{l}r U_{E-10}+\beta\left[y x-r U_{E-10}\right]-(1-\beta)\left[U_{E T}-U_{E-10}\right] i=0 \\ r U_{E-(i+1) 0}+\beta\left[y x-r U_{E-(i+1) 0}\right]-(1-\beta)\left[U_{E-i 0}-U_{E-(i+1) 0}\right], i=1, \ldots, E-1\end{array}\right.$ 
(ii) Since newly filled jobs produce with the productivity $x=1$ a job seeker with the counter $E-i$ and a residual benefit duration of $T-j$ periods, $j=i, \ldots, T$, obtains the outside wage

$$
W_{E-i T-j}=\left\{\begin{array}{l}
W_{E+1}(1)-(1-\beta)\left(U_{E T}-U_{E T-j}\right) \rho^{-1}, \quad i=0 \\
W_{E-(i-1)}(1)+(1-\beta)\left(U_{E-i T-j}-U_{E-i 0}\right) \rho^{-1}, \quad i=1, \ldots, E
\end{array}\right.
$$

where $w_{E+1}(1)$ and $w_{E-(i-1)}(1)$ are the inside-wages (29) and (30) for $x=1$.

The inside wage $w_{E-i}(x)$ of a worker with the counter $E-i$ has - as (30) shows - three components: the reservation income, $r U_{E-(i+1) 0}$, the worker's share of the current match rent, $\beta\left[y x-r U_{E-(i+1) 0}\right]$, and the side payment $(1-\beta)\left[U_{E-i 0}-U_{E-(i+1) 0}\right]$. To understand the reason for the side payment notice that at the end of the current period, the worker has $E-(i+1)$ qualifying points and the reservation value $U_{E-(i+1)}$. If the match is continued, the counter increases by one to $E-i$ and the reservation value of the human capital increases by the qualifying rent $U_{E-i 0}-U_{E-(i+1) 0}$. The firm, which employs the worker, appropriates the share $1-\beta$ of the qualifying rent. The qualifying rent is the result of institutional frictions, which emerge from the prevailing order of the labor law. In accordance with assumption ( $A 2)$, the qualifying period is an asset owned by the worker, which is not tradable. Thus, since the labor force is exogenous, a dissipation of the qualifying rent is generally excluded, even in the steady state.

If one compares, ceteris paribus, two agents with a completed qualifying period $(i=0)$ - one is an outsider, the other an insider - then, as we would expect, the outsider is worse off, because, as opposed to the insider, he has to pay a side payment, as seen in the first line of (31). The size of the payment is determined by the length $j$ of the current spell of unemployment and the quasi-rent $U_{E T}-U_{E T-j}$, by which the reservation value of the outsider is lower than the reservation value of the insider.

Now compare two agents with the counter $E-i$ who have not yet completed their qualifying period - where one is an outsider with a residual entitlement of $T-j$ periods, the other is an insider - then the outsider is better off, since he receives a wage bonus, which is dependent on the quasi-rent $U_{E-i T-j}-U_{E-i 0}$, as the second line of (31) shows. The insider is 
worse off, because his qualifying period is not yet completed and, as a result, in accordance with assumptions ( $A 1)$ and (A2), he has no benefit entitlement - as opposed to the outsider.

As the following proposition shows, the market value of a filled job $\Pi_{E-(i-1)}(x), i=0, \ldots, E$, is a continuously increasing function of $x \in[\alpha, 1]$. If $\Pi_{E-(i-1)}(\alpha) \leq 0$, as we assume throughout, a reservation productivity $R_{E-(i-1)}$ exists, which fulfils the reservation condition

$$
\Pi_{E-(i-1)}\left(R_{E-(i-1)}\right)=0, i=0, \ldots, E .
$$

The asset values of the filled jobs and the job destruction rules are discussed in the following proposition, which is proved in the Appendix III.

Proposition (i) [Filled J obs]. The value of a filled job with a completed qualifying period and the idiosyncratic productivity $x \in\left[R_{E+1}, 1\right]$, is

$$
\Pi_{E+1}(x)=(1-\beta) y \frac{x-R_{E+1}}{\lambda+r} .
$$

Through backward induction, the continuity and monotonicity of $\Pi_{E+1}(x)$ are transferred to $\Pi_{E-i}(x)$, as the Equation (34) shows. The value of a job from the pool $e_{E-i}, i=0, \ldots, E-1$, is

$$
\Pi_{E-i}(x)=\rho\left\{(1-\beta) y\left(x-R_{E-i}\right)+(1-\lambda)\left[\max \left\{0, \Pi_{E-(i-1)}(x)\right\}-\max \left\{0, \Pi_{E-(i-1)}\left(R_{E-i}\right)\right\}\right]\right\} .
$$

(ii) [Job Destruction]. For a job with a completed qualifying period, the job destruction rule can be derived by evaluating the asset Equation (23) at the reservation threshold $x=R_{E+1}$. Taking into account the wage Equation (29) we obtain:

$$
R_{E+1}=\frac{r U_{E T}}{y}-\frac{\lambda}{(1-\beta) y} \int_{R_{E+1}}^{1} \Pi_{E+1}(h) d G(h) .
$$

For a job with the qualifying counter $E-i$, the job destruction rule can be derived from the asset Equation (25), the reservation condition (32) and the wage Equation (30) with

$$
R_{E-i}=\left\{\begin{array}{c}
\frac{r U_{E-10}}{y}-\frac{U_{E T}-U_{E-10}}{y}- \\
\frac{1}{(1-\beta) y}\left[\lambda \int_{R_{E+1}}^{1} \Pi_{E+1}(h) d G(h)+(1-\lambda) \max \left\{0, \Pi_{E+1}\left(R_{E}\right)\right\}\right], \quad i=0 \\
\frac{r U_{E-(i+1) 0}}{y}-\frac{U_{E-i 0}-U_{E-(i+1) 0}}{y}- \\
\frac{1}{(1-\beta) y}\left[\lambda \int_{R_{E-(i-1)}}^{1} \Pi_{E-(i-1)}(h) d G(h)+(1-\lambda) \max \left\{0, \Pi_{E-(i-1)}\left(R_{E-i}\right)\right\}\right], i=1, \ldots, E-1
\end{array}\right.
$$


As the Equations (35) and (36) show, the current reservation output of a match is lower than the match's permanent reservation income both during the waiting time of the worker, see Equations (36), and also after the completion of the qualifying period, see Equation (35). The reservation income of a match - given the assumption of free disposal and the infinitely elastic supply of vacancies - is identical with the reservation income of the worker.

With the job termination rule (35), the firm chooses the reservation productivity $R_{E+1}$ such that $y R_{E+1}<r U_{E T}$ for the reservation output of the match. The firms are willing to hoard labor, even if hit by severe demand shocks. The reasons for this behavior are the search costs and the resulting option value of a filled job. The option value is the expected market value of a productive job weighted with the shock probability $\lambda$. If demand changes in favor of the job, the hoarded workers are immediately ready to start production, since neither search nor recruiting costs arise on the 'internal labor market'. If the match partners would separate as soon as the output falls below the reservation income of the match, they would sacrifice this option and have to search for another match.

The waiting time is the time that passes until a worker on the qualifying path becomes eligible to UB. Under the conditions of the unemployment insurance $[E, \gamma, T, b]$, the waiting time is endogenous, whereby workers face the following trade-off.

The shock parameter $x \in[\alpha, 1]$ is bounded from below. Consequently, a match can force the continuation of production until the $\mathrm{UI}$ entitlement is reached. Thus, for example, a worker with the qualifying counter $E-i$ can reduce his waiting time to exactly $i$ periods, if the firm fixes the reservation productivity along the residual qualifying path at the level of the lower support $\alpha$. By taking this decision, however, the worker must accept a low, possibly negative wage, what pays only if he can expect a high UB $b$, a long benefit duration $T$ or a low utility of leisure $z$.

The worker will weigh the disadvantages of restraining his wage claims against the benefit from a reduction in the waiting time. His willingness to restrain his wage claims during the waiting time - as the job destruction rule (36) shows - is bounded by the path of the reservation incomes, the 
qualifying rents he can expect to capture and the option value of the filled job.

The option value of the filled job is measured by the integral expression in Equation (36). Since the worker makes a transition independent of the prevailing market conditions from $e_{E-i}$ to $e_{E-(i-1)}$ when the job is continued, the lower bound of the integral is the reservation productivity $R_{E-(i-1)}$ that is the threshold productivity for the transition to $e_{E-(i-1)}$.

If the firm currently produces at the break-even point with the reservation productivity $R_{E-i}$ and is not hit by a shock - an event which has the probability $1-\lambda$ - the firm opts for the alternative $\max \left\{0, \Pi_{E-(i-1)}\left(R_{E-i}\right)\right\}$ as a consequence of the free disposal.

Finally, the worker's willingness to accept a sequence of low wages on the qualifying path is bounded by the qualifying rents. If the firm chooses the reservation productivity $R_{E-i}$, it takes the worker's reservation value $U_{E-(i+1) 0}$ into account. If the match is continued, the reservation value of the worker increases to $U_{E-i 0}$. In order to capture the qualifying rent $U_{E-i 0}-U_{E-(i+1) 0}$ created by the insurance system, the worker is willing to accept a reduction of the reservation output of the match by an amount just equal to the rent.

\subsection{Solution}

To solve the model, we must determine the equilibrium path of the reservation productivities $R_{E-(i-1)}, i=0, \ldots, E$, and the steady state tightness $\theta$ of the labor market - in total $E+2$ variables. The reservation productivities depend on the reservation wages of the workers, the qualifying rents and the market values of the filled jobs, as the job destruction rules (35) and (36) show. The market values of the filled jobs are in turn functions of the reservation productivities, as Equations (33) and (34) show. In order to close the model, Lemma A6 in Appendix IV makes clear how both the reservation wages of the workers and the qualifying rents depend on the market values of the filled jobs and, thus, the reservation productivities. To calculate the tightness $\theta$, we need the job creation condition (28). The conditional probabilities $\mu_{E-i T-j}$ of meeting a job seeker with the qualifying 
counter $E-i$ and a residual benefit duration of $T-j$ periods are developed in Lemma A4 in Appendix IV.

\section{Simulation}

Parameters and matching function. The base line parameters for the numeric simulations are shown in Table 2. The bargaining power of the workers is $\beta=0.50$, the output of a job at full productivity is $y=100$. The value of leisure is $z=30$, UB are $b=30$. The real interest rate $r$ is $2 \%$; the probability of a productivity shock $\lambda$ is $10 \%$; the search and recruiting costs of a vacancy amount to $k=30$. The distribution function $G(x)$ of the productivity shocks is assumed to be uniform on $[\alpha, 1]$, with the lower support $\alpha=0$. If we replace the uniform distribution by a beta distribution with varying parameter values we receive for all simulations similar results. The matching function of the search market is of the CobbDouglas type (Petrongolo/Pissarides 2001). For a given vacancy, the probability of a contact with a job seeker is $q(\theta)=\delta \theta^{-(1-\phi)}$. For the elasticity of the job matches with respect to the supply of vacancies, we use $\phi=0.50$ and for the 'total factor productivity' we assume $\delta=0.60$.

Table 2: The baseline parameter of the model

\begin{tabular}{|c|c|c|c|c|c|c|c|c|c|}
\hline$\beta$ & $r$ & $\lambda$ & $y$ & $z$ & $b$ & $k$ & $\alpha$ & $\phi$ & $\delta$ \\
\hline 0.50 & 0.02 & 0.10 & 100 & 30 & 30 & 30 & 0 & 0.50 & 0.60 \\
\hline
\end{tabular}

The results of the simulations with the qualifying period $E$, the benefit duration $T$ and the base period $\gamma$ are shown in Appendix I. Figures 2-4 provide simulations with the benefit duration $T$ and the qualifying period $E$ for a given base period $\gamma=0.10$. For the qualifying period, we assume $E=4,8$ and for the benefit duration $T=1,2, \ldots, 20$. In addition, Appendix I compares the two unemployment insurance systems $[E, \gamma, T, b]$ and $[T, b]$ (see Section 2 ). With the unemployment insurance $[T, b]$, every employed worker is entitled to up to $T$ payments of the UB $b$. The model of the unemployment insurance $[T, b]$, therefore, implicitly assumes that for the qualifying period $E=1$ and the base period $\gamma=1$. Figures $5 \mathrm{a}-\mathrm{c}$ deal with comparative static simulations with the base period $\gamma$ for a benefit duration of $T=10$ periods and the qualifying periods $E=4,8$. 
Result 1 [Decreasing Qualifying Path $\Psi_{E}=\left[R_{2}, \ldots, R_{E}\right]$ ]. Figure 2a, Appendix I, shows the qualifying paths $\Psi_{E}$ for $E=4$ and $E=8$, a benefit duration of $T=10$ periods and a base period $\gamma=0.10$. The counter of the qualifying period, $i=1, \ldots, E+1$, is depicted on the horizontal axis and the corresponding reservation productivities are graphed on the vertical axis. For example, figure $2 \mathrm{~b}$ pictures, for the case $E=4$, the four reservation productivities of the qualifying path $\Psi_{4}$ and the reservation productivity $R_{E+1}$ of the jobs with a completed qualifying period, against the benefit duration $T$ on the horizontal axis.

As Figure $2 \mathrm{a}$ and $2 \mathrm{~b}$ demonstrate, the qualifying path $\Psi_{E}$ follows the same pattern in all simulations: First, the qualifying paths are concave and to reap the qualifying rents firms reduce the reservation productivities $R_{E-(i-1)}, i=0, \ldots, E$, until they reach a minimum in the last period before the completion of the qualifying period. Second, as soon as firm and worker have captured all rents and the worker is entitled to the UB, the reservation productivity, the quit rate and the wage of the employed worker jump to the levels of the jobs with a completed qualifying period, such that $R_{E+1}>R_{1}>R_{2}>\ldots>R_{E} \geq \alpha$. If we draw a vertical line through Figure $2 \mathrm{~b}$ at $T=10$, we obtain the qualifying path $\Psi_{4}$ for $E=4$, which is shown in Figure $2 a$.

Result 2 [Benefit Duration 7 ]. The benefit duration $T$ affects $u$ via two channels: First, through the weighted ex-post-incidence, In$\operatorname{exP} \equiv(1-p) \sum_{i=0}^{i=E-1} \lambda G\left(R_{E-(i-1)}\right) \varepsilon_{E-i}$, and second, through the expected unemployment duration $D=1 / p$. In-exP, the weighted ex-post-incidence, is the fraction of the employed workers who lose their job, do not find a followup job at the subsequent matching and, as a result, are unemployed for at least one period.

Consider, for example, the insurance system with the qualifying period $E=4$. If the policymakers increase the benefit duration from $T=1$ to $T=20$, the expected duration of unemployment increases from $D=1.84$ periods to $D=2.17$ periods, see Figure $3 a$, while the ex-post-incidence grows from $4.1 \%$ to $4.8 \%$, see Figure $3 \mathrm{~b}$. For a given qualifying period $E$ therefore, the unemployment rate $u$ strictly increases with the benefit du- 
ration $T$, see Figure 3c. For $E=4$, for example, the equilibrium rate of unemployment increases from $7 \%$ to $9.5 \%$, if the benefit duration rises from $T=1$ to $T=20$.

Result 3 [Qualifying Period E]. An extension of the qualifying period $E$ for a given base period $(\gamma=0.10)$ lowers the unemployment rate, as Figure $3 c$ and Figure 4 make clear.

The unemployment rate strictly decreases with an increasing $E$, since, ceteris paribus, both the unemployment duration and the weighted ex-postincidence decrease with the rising $E$, see Figure $3 a$ and Figure $3 b$. For example, with $\gamma=0.10$ and $T=10$ the unemployment rate falls from $u=9.74 \%$ to $u=9.13 \%$, if the qualifying period $E$ increases from 1 to 10 calendar periods.

Result 4 [Comparison Between the Insurance Systems]. The insurance system $[T, b]$ implicitly sets $E=1$ and $\gamma=1$, such that $u$ is strictly higher than in the insurance systems with qualifying periods $E \geq 2$, see the dotted lines in the Figures 3a-c. The reasons for the increasing difference between the equilibrium rates of unemployment of the two insurance systems are, that under the conditions of the insurance $[E, \gamma, T, b]$ not only is the average duration of unemployment shorter than in the system $[T, b]$ but the ex-post-incidence is also lower. What are the reasons for this ordering?

The risk-neutral match partners have rational expectations and anticipate the consequences of job destruction. In the insurance system $[E, \gamma, T, b]$, the destruction of a job that qualifies for UB occurs with the endogenous probability $\lambda G\left(R_{E+1}\right)$, whereas in the system $[T, b]$ the probability is $\lambda G(R)$, where $\lambda G(R)>\lambda G\left(R_{E+1}\right)$. In fact, the workers in both insurance systems are entitled to the UB $b$ and an equally long benefit duration of $T$ periods. Furthermore, in both insurance systems, they have a positive probability of losing their benefit entitlement and to become long term unemployed. Yet with the unemployment insurance $[T, b]$, they can be sure of having the benefit entitlement regained with their next job. Moreover, the waiting time, which elapses until a worker who loses his current job receives the next benefit entitlement, is under $[T, b]$ identical with the duration of job 
search, which is equal to $1 / p$. In the insurance system $[E, \gamma, T, b]$, on the other hand, a positive probability exists that the worker with an increasing duration of unemployment will not only lose his benefit entitlement, but also his qualifying points, so that, on average, ceteris paribus more time will pass until the completion of the next qualifying period than just the time of the job search, which is the lower bound for the waiting time.

While the waiting time which elapses between two benefit entitlements in the system $[T, b]$ is exogenous for the individual match and identical with the expected duration of job search, $1 / p$, from the perspective of the job seeker, the waiting time in the insurance system $[E, \gamma, T, b]$ is endogenous and bounded from below by the expected duration of an unemployment spell. As a consequence, the reservation wage of a worker entitled to UB is, ceteris paribus, lower in the insurance system $[E, \gamma, T, b]$ than in the unemployment insurance $[T, b]$, his wage income is also lower and his willingness to continue the match despite adverse demand shocks is higher.

Result 5 [Base Period and Convergence]. Figure 5a-c illustrate the impact of the base period $\gamma$ on the (weighted) ex-post-incidence, see Figure $5 a$, the unemployment duration, see Figure $5 b$, and the equilibrium unemployment rate, see Figure 5c. Just for comparison, the figures show the corresponding graphs for the unemployment insurance $[T, b]$.

As Figure $5 c$ shows, the equilibrium rate of unemployment strictly increases with the base period $\gamma$. An increase in $\gamma$ does not only lower the waiting time, but also the qualifying rents and therefore the option value of a filled job. Moreover, the expected wage income increases, the supply of vacancies falls and, as a result, both the duration of unemployment, see Figure 5b, and the weighted ex-post-incidence, see Figure $5 \mathrm{a}$, increase.

In addition, Figure 5a-c illustrate that the equilibrium values of the expost incidence, the unemployment duration and hence the unemployment rate in the class of insurance systems $[E, \gamma, T, b]$ with $E \geq 2$, converge with rising $\gamma$ from below to the corresponding values of the insurance $[T, b]$. 
Result 6 [Iso-Unemployment Curve $u=9.5 \%$ ]. The insurance system $[E, \gamma, T, b]$ consists of four policy parameters. The 'iso-unemployment curves' in the policy space are therefore four-dimensional hyperplanes. Figures 6a-c depict three-dimensional $(\gamma, E, T)$-sectors of the iso-unemployment curve for $u=9.5 \%$. Figure $6 \mathrm{~b}$ illustrates the $(\gamma, E, T)$-plane for an UB of $b=30$, while Figures $6 a$ and $6 c$ show the corresponding $(\gamma, E, T)$-planes for a $5 \%$ reduction of the UB to $b=28.5$ and a $5 \%$ increase of the UB to $b=31.5$ respectively.

Figures 7a-c and 8a-c graph two-dimensional sectors of the isounemployment curve $u=9.5 \%$. Figure 7 a shows the negative trade-off between the UB $b$ and the benefit duration $T$ for the base periods $\gamma=0.10$ and $\gamma=0.60$, where $E=4$; for $T=10$ Figure $7 \mathrm{~b}$ depicts the positive trade-off between the UB $b$ and the qualifying period $E$, where for the base periods $\gamma=0.10, \gamma=0.30$ and $\gamma=0.60$; Figure $7 \mathrm{c}$ shows the positive trade-off between the benefit duration $T$ and the qualifying period $E$ for the base periods $\gamma=0.10$ and $\gamma=0.30$. Figures 8a-c depict the base period $\gamma$ on the vertical axis and the UB $b$, the benefit duration $T$ and the qualifying period $E$ on the horizontal axes. Figure 8 a shows the negative trade- off between the UB $b$ and the length of the base period $\gamma$, Figure $8 \mathrm{~b}$ graphs the negative trade-off between the benefit duration $T$ and the base period $\gamma_{1}$ and Figure $8 c$ finally shows the positive trade-off between the base period $\gamma$ and the qualifying period $E$.

\section{Conclusion}

Base period and qualifying period are instruments of the labor market policy, which have so far received little attention in labor market theory, macroeconomic theory and empirical research. We develop a MortensenPissarides type search model, in which we integrate the following policy instruments: The base period, the qualifying period, the unemployment benefit and a finite benefit duration. A worker is entitled to UB, if he has completed the statutory qualifying period within the base period.

The qualifying period lowers both the incidence and the duration of unemployment and therefore reduces the aggregate unemployment rate. On the other hand, an increasing base period weakens the effect of the quali- 
fying period by providing workers with a time margin to meet the criterion of the qualifying rule. The longer the base period, the higher therefore the equilibrium rate of unemployment.

In an unemployment insurance system without qualifying rule - as for example in the standard MP-model - the time that passes until the benefit entitlement occurs is exogenous. Every worker, who makes a transition to unemployment, is entitled to UB and every job seeker must wait until he finds a new job and in turn the next benefit entitlement. The qualifying period endogenizes the waiting time and confronts the workers with the following trade-off. The lower the separation rates negotiated by the match, the longer the durability of the job, the shorter the waiting time, but also the lower the worker's wage. The decision to reduce the waiting time is more attractive the higher the UB are, the longer the benefit duration and the lower the utility of leisure. The price for a prolongation of the durability of the job and a shorter waiting time is the wage penalty, which the worker must accept, if the match is hit by adverse productivity or demand shocks.

For a match on the qualifying path, the separation rate falls from period to period, until it reaches a minimum in the last time period before the completion of the qualifying criterion. At this point, the qualifying rents created by the unemployment insurance are skimmed off, and the reservation productivity and with it the separation rate and the wage of the workers, who are now entitled to UB, increase sharply.

\section{References}

Atkinson, A.B./Micklewright, J. (1991): Unemployment compensation and labor market transitions: a critical review, Journal of Economic Literature 29, 1679-1727.

Layard, R./Nickell, S./J ackman, R. (1991): Unemployment: Macroeconomic performance and the labour market, Oxford University Press, Oxford.

Mortensen, D.T. (1977): Unemployment insurance and job search decisions, Industrial and Labor Relations Review 30, 505-517.

Mortensen, D.T./Pissarides, C.A. (1994): Job Creation and J ob Destruction in the Theory of Unemployment, Review of Economic Studies 66, 397415. 
Mortensen, D.T./Pissarides, C.A. (1999): New Developments in Models of Search in the Labour Market, in: O. Ashenfelter/Card, D. (eds.): Handbook of Labour Economics, Vol. 3B, Amsterdam, 2567-2627.

Nickell, S./Layard, R. (1999): Labour market institutions and economic performance, in: Ashenfelter, O./Card, D. (eds.): Handbook of Labour Economics, Vol. 3C, North-Holland, Amsterdam, 3029-3084.

Nickell, S./Nunziata, L./Ochel, W. (2005): Unemployment in the OECD since the 1960s. What do we know? The Economic Journal 115, 1-27.

OECD (2004): Benefits and Wages: OECD Indicators, Paris.

Petrongolo, B./Pissarides, C.A. (2001): Looking into the Black Box: A Survey of the Matching Function, J ournal of Economic Literature 39, 390431.

Pissarides, C.A. (2000): Equilibrium Unemployment Theory, 2. Edition, Oxford University Press, Oxford.

Rogerson, R./Shimer, R./Wright, R. (2005): Search-Theoretic Models of the Labor Market: A Survey, J ournal of Economic Literature 43, 959988. 


\section{Appendix I}

Results 1 and 2

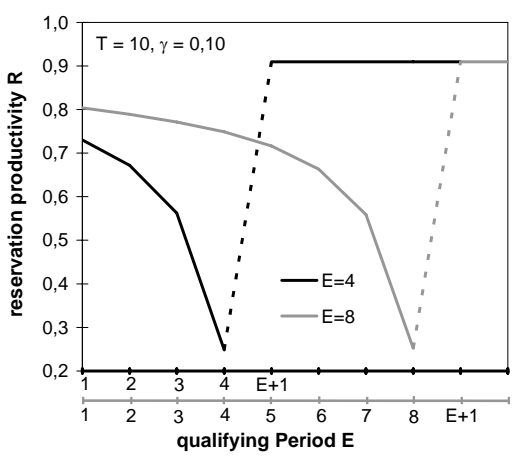

Figure $2 \mathrm{a}$

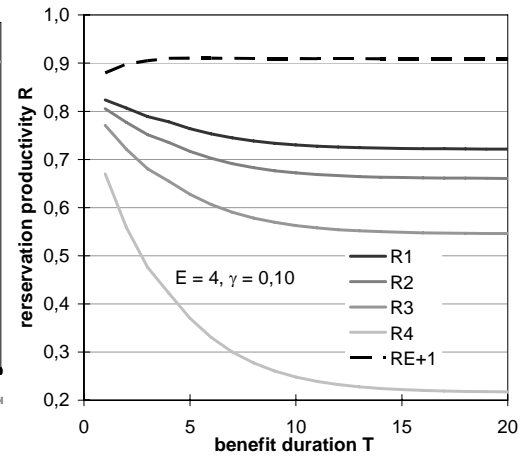

Figure 2b

\section{Results 3 and 4}

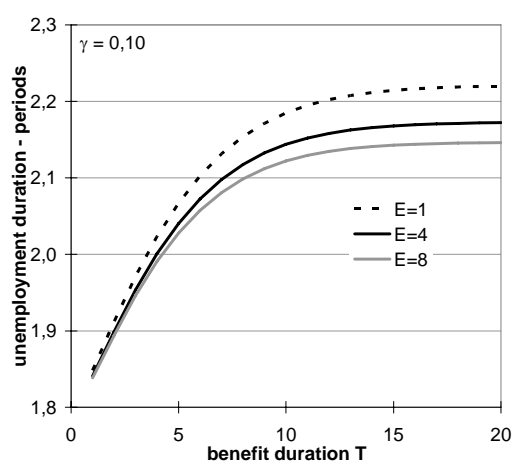

Figure $3 a$

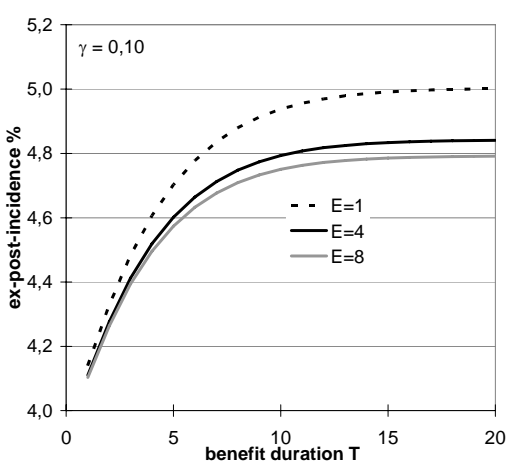

Figure $3 b$

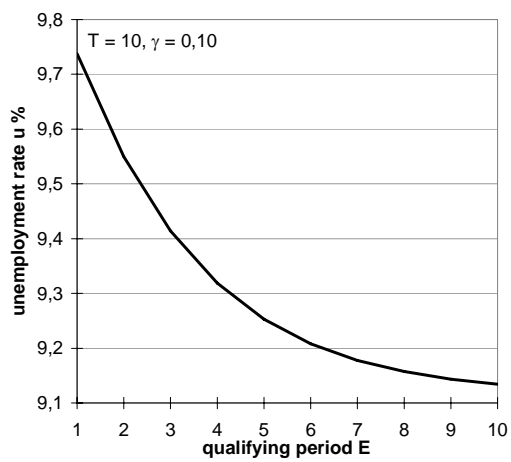

Figure 4

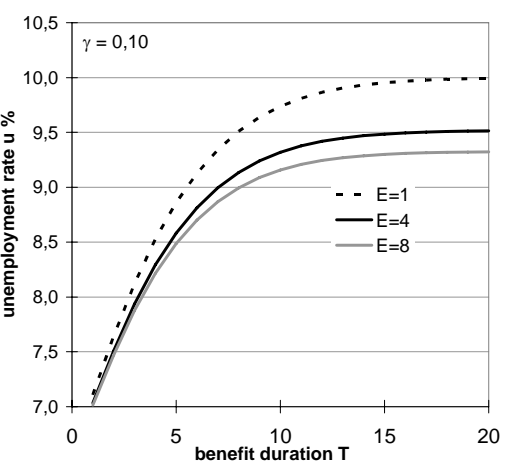

Figure 3c 


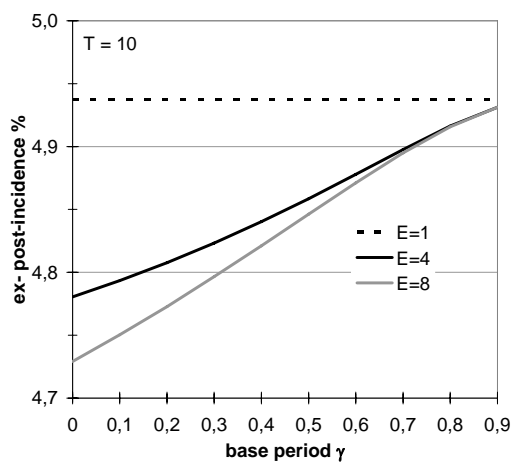

Figure $5 a$

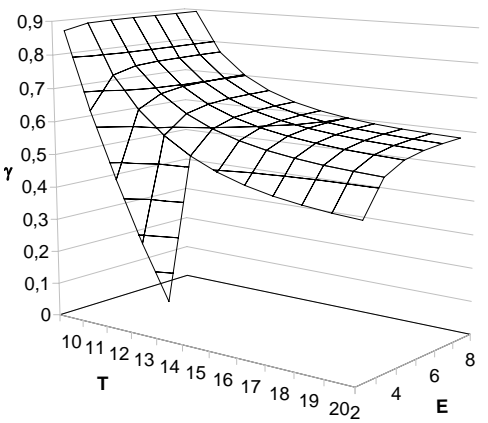

Figure $6 a: b=28.5$

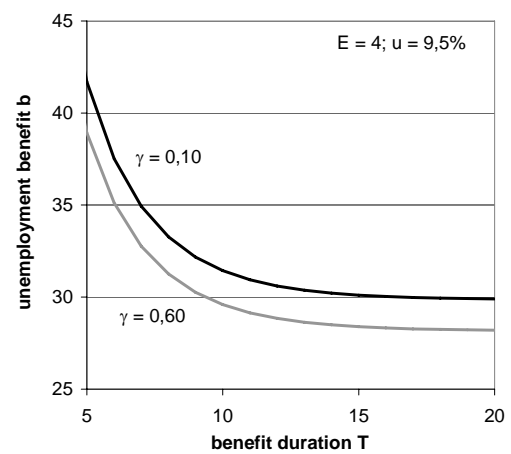

Figure $7 a:(T, b)$

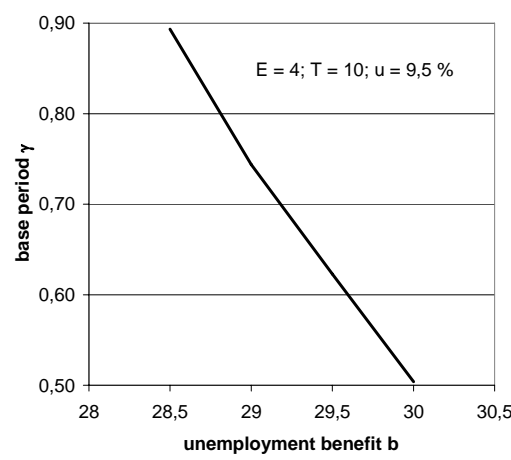

Figure $8 \mathrm{a}:(b, \gamma)$
Result 5

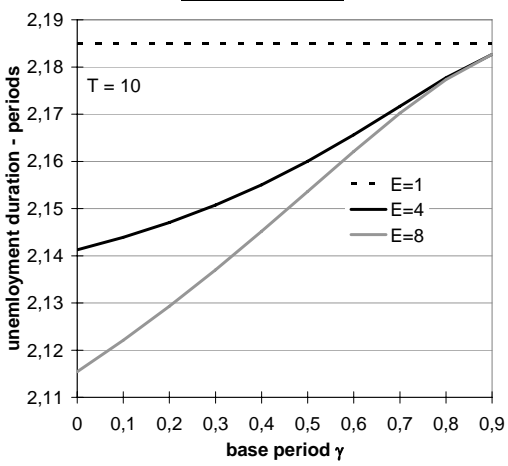

Figure 5b

Result 6: $u=9.5 \%$

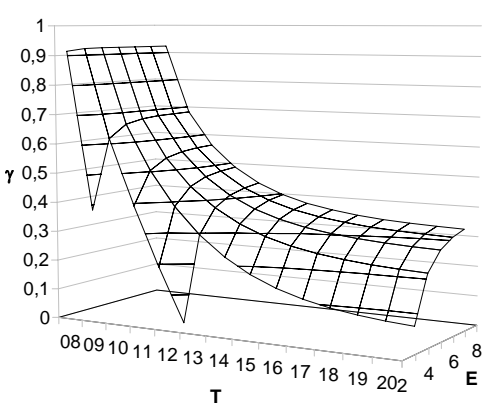

Figure $6 \mathrm{~b}: b=30$

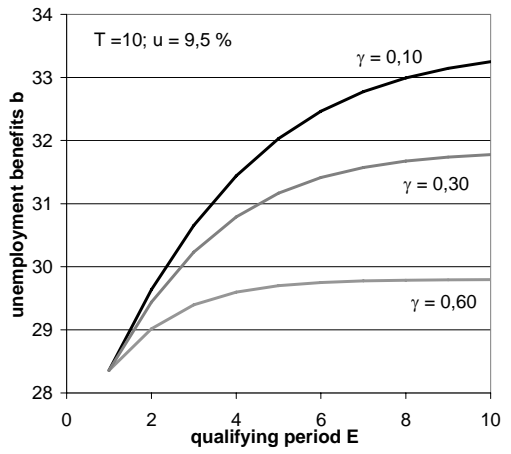

Figure $7 b:(E, b)$

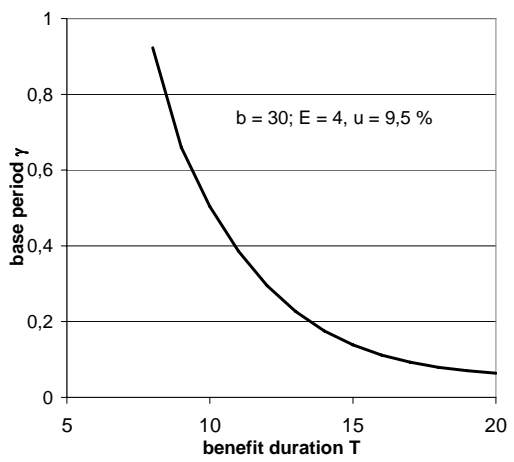

Figure $8 b:(T, \gamma)$

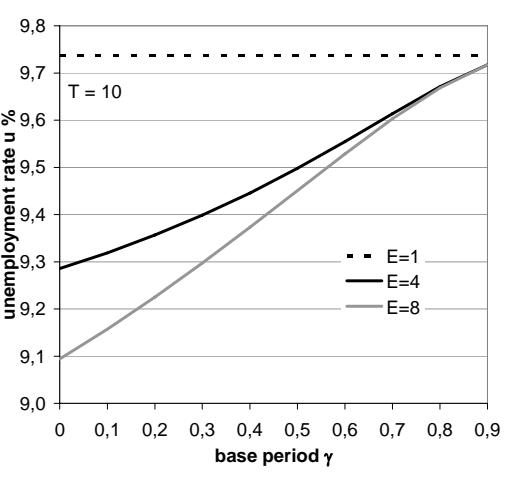

Figure 5c

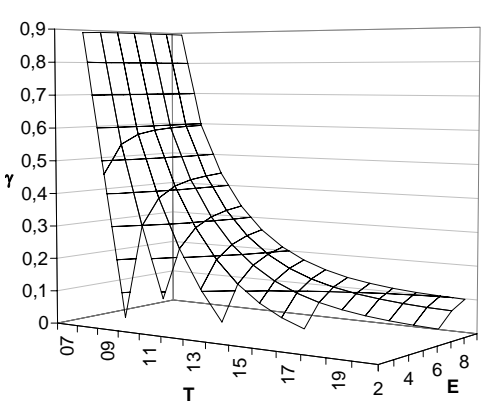

Figure $6 c: b=31.5$

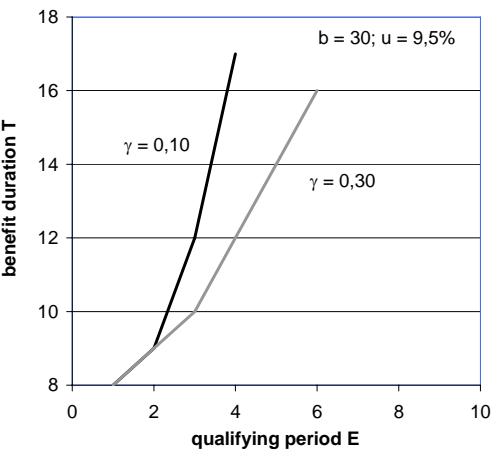

Figure $7 c:(E, T)$

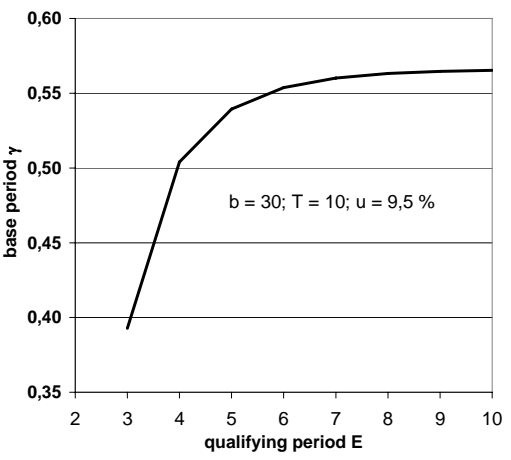

Figure 8c : $(E, \gamma)$ 


\section{Appendix II}

Proof of Lemma 1. (i): From (14), it follows that

$(1-\beta) U_{T}=(1-\beta) W(x)-\beta \Pi(x)$. Solve the asset Equations (6) and (7) with respect to $\Pi(x)$ and $W(x)$, insert the solutions into the above equation and rearrange terms to get the inside wage (16).

(ii) From (15), it follows that $(1-\beta) U_{T-j}=(1-\beta) W_{T-j}-\beta \Pi_{T-j}$. Inserting (8) and (9) into the last equation gives

$(1-\beta) U_{T-j}=[(1-\beta) W(1)-\beta \Pi(1)]+\rho\left[w_{T-j}-w(1)\right]$, from which in view of (14) the outside wage (17) follows.

Proof of Lemma 2. (i) and (ii): From (5) and (6) we have $0=y R-w(R)+\lambda \int_{R}^{1} \Pi(h) d G(h)$. From this equation, taking (16) and (6) into account we obtain the Equations (18) and (19).

Proof of Lemma 3. (i) From (13), (15), (8) and the wage Equation (17), it follows that

$$
U_{T-j}=D+d\left[z+b+U_{T-(j+1)}\right]
$$

where $D \equiv \frac{\beta p}{(1-\beta)[1-(1-\beta) p]}\left[\Pi(1)+(1-\beta) U_{T}\right]$ and $d \equiv \frac{(1-p) \rho}{1-(1-\beta) p}$. Solving the difference Equation ( $A 1)$ gives:

$$
U_{T-j}=\frac{1-d^{T-j}}{1-d}[D+d(z+b)]+d^{T-j} U_{0}
$$

In the same way, it follows from (12), (15), (8) and (17) for $U_{0}$ :

$$
U_{0}=\frac{(1-p) \rho}{(1-\beta)[(1-p) r \rho+\beta p]} z+\frac{1-(1-\beta) p}{(1-p) r \rho+\beta p} D
$$

Using $(A 3)$ in $(A 2)$ gives:

(A4) $\quad U_{T-j}=\frac{(1-p) \rho}{(1-p) r \rho+\beta p}\left[z+b\left(1-d^{T-j}\right)\right]+\frac{\beta p}{(1-\beta)[(1-p) r \rho+\beta p]}\left[\Pi(1)+(1-\beta) U_{T}\right]$.

From (A4) we obtain the asset Equation (20).

(ii) The Equation (21) follows directly from (8) and (17). 
Appendix III

The sharing rule for wage negotiations between a vacancy and a job seeker is given by

$$
W_{E-i T-j}-U_{E-i T-j}=\frac{\beta}{1-\beta} \Pi_{E-i T-j}, i=0, \ldots, E, j=i, \ldots, T,
$$

where $W_{E-i T-j}$ is the value of a entrant with $E-i$ qualifying points and a residual benefit duration of $T-j$ periods, $U_{E-i T-j}$ is the value of the unemployed outsider, and $\Pi_{E-i T-j}$ is the initial value of a job occupied by an entrant with the characteristics $[E-i, T-j] . \Pi_{E-i T-j}$ depends on the job seeker's residual claims and the current status of the qualifying counter, where in view of the initial productivity $x=1$, the outside wage $w_{E-i T-j}$ and the asset Equations (23) and (25):

$$
\Pi_{E-i T-j}=\left\{\begin{array}{l}
\Pi_{E+1}(1), \quad i=j=0 \\
\Pi_{E-(i-1)}(1)+\rho\left[w_{E-(i-1)}(1)-w_{E-i T-j}\right], \quad i=0, \ldots, E, j=i, \ldots, T-1 \\
\Pi_{E-(i-1)}(1), \quad i=1, \ldots, E, j=T
\end{array}\right.
$$

For the distribution of the initial values of the job seekers, $W_{E-i T-j}$, analogously we have:

(A7) $W_{E-i T-j}=\left\{\begin{array}{l}W_{E-(i-1)}(1)+\rho\left[W_{E-i T-j}-W_{E-(i-1)}(1)\right], \quad i=0, \ldots, E, j=i, \ldots, T-1 \\ W_{E-(i-1)}(1), \quad i=1, \ldots, E, j=T\end{array}\right.$

Finally, the distribution of the steady state values of the job seekers is given by:

(A8)

$$
U_{E-i T-j}=\left\{\begin{array}{l}
p W_{00}+(1-p) \rho\left[z+U_{00}\right], \quad i=E, j=T \\
p W_{E-i 0}+(1-p) \rho\left[z+\gamma U_{E-i 0}+(1-\gamma) U_{E-(i+1) 0}\right], \quad i=0, \ldots, E-1, j=T \\
p W_{E-i T-j}+(1-p) \rho\left[z+b+\gamma U_{E-i T-(j+1)}+\right. \\
\left.\quad(1-\gamma) U_{E-(i+1) T-(j+1)}\right], \quad i=0, \ldots, E-1, j=i, \ldots, T-1 \\
p W_{0 T-j}+(1-p) \rho\left[z+b+U_{0 T-(j+1)}\right], i=E, j=E, \ldots, T-1
\end{array}\right.
$$

In (A8) $z$ is the utility of leisure, $b$ the UB and $\gamma \in[0,1)$ the length of the base period. If the job seeker does not meet a vacancy, his current spell of unemployment increases from length $j$ to $j+1$, while the counter of the 
qualifying period is constant with probability $\gamma<1$ and decreases from $E-i$ to $E-(i+1)$ by one point with probability $1-\gamma>0 .{ }^{7}$

Proof of Lemma 4. (i) From the sharing rule (14), it follows that:

$(1-\beta) W_{E+1}(x)-\beta \Pi_{E+1}(x)=(1-\beta) U_{E T}$. Using the asset Equations (23) - (24) and rearranging terms provides the wage Equation (29). For convenience, we repeat the equation below:

(A9)

$$
w_{E+1}(x)=r U_{E T}+\beta\left(y x-r U_{E T}\right) .
$$

From the sharing rule (27), it follows that:

$(1-\beta) W_{E-i}(x)-\beta \Pi_{E-i}(x)=(1-\beta) U_{E-(i+1) 0}, i=0, \ldots, E-1$. If we use the asset

Equation (25) and assume $i=0$, then by virtue of the first line of (26) and (A9), we obtain the first line of the wage Equation (A10) below. The other wage equations of (A10) for $i=1, \ldots, E-1$ result analogously:

(A10)

$$
W_{E-i}(x)=\left\{\begin{array}{l}
W_{E+1}(x)-(1-\beta)\left(U_{E T}-U_{E-10}\right) \rho^{-1}, \quad i=0 \\
W_{E}(x)-(1-\beta)\left(U_{E-10}-U_{E-20}\right) \rho^{-1}+(1-\beta)\left(U_{E T}-U_{E-10}\right), \quad i=1 \\
W_{E-(i-1)}(x)-(1-\beta)\left(U_{E-i 0}-U_{E-(i+1) 0}\right) \rho^{-1}+ \\
(1-\beta)\left(U_{E-(i-1) 0}-U_{E-i 0}\right), i=2, \ldots, E-1
\end{array}\right.
$$

The wage Equation (30) is developed in the following way. For $i=0$, we get from (A10): $W_{E}(x)=W_{E+1}(x)-(1-\beta) \rho^{-1}\left(U_{E T}-U_{E-10}\right)$. If we replace $w_{E+1}(x)$ using (A9), we get in view of $\rho^{-1}=1+r$ the first line of (30):

$W_{E}(x)=r U_{E T}+\beta\left(y x-r U_{E T}\right)-(1-\beta) \rho^{-1}\left(U_{E T}-U_{E-10}\right)=$ $(1-\beta) r U_{E T}+\beta y x-(1-\beta) \rho^{-1}\left(U_{E T}-U_{E-10}\right)=r U_{E-10}+\beta\left(y x-r U_{E-10}\right)-$

$(1-\beta)\left(U_{E T}-U_{E-10}\right)$. Now we assume that the wage Equation (30) holds for $w_{E-(i-1)}(x)$. Then for $w_{E-i}(x)$, we obtain with $(\mathrm{A} 10)$ :

$W_{E-i}(x)=W_{E-(i-1)}(x)-(1-\beta)\left(U_{E-i 0}-U_{E-(i+1) 0}\right) \rho^{-1}+(1-\beta)\left(U_{E-(i-1) 0}-U_{E-i 0}\right)$. If we replace $w_{E-(i-1)}(x)$ using (30) and rearrange, we obtain the wage equation for $E-i$.

(ii) Rewrite the sharing rule (A5): $(1-\beta) W_{E-i T-j}-\beta \Pi_{E-i T-j}=(1-\beta) U_{E-i T-j}$, and insert the asset Equations (A6) and (A7) to obtain the wage Equations (31).

7 The job seeker - like B in the introductory example - was unemployed $F$ periods ago and in the second case - like A in the introductory example - he was employed $F$ periods ago. 
Proof of the Proposition. (i) If we solve the asset Equation (23) for $\Pi_{E+1}(x)$ and take the wage Equation (29) into account, we obtain:

$$
\Pi_{E+1}(x)=\frac{1}{\lambda+r}\left\{(1-\beta) y x-(1-\beta) r U_{E T}+\lambda \int_{R_{E+1}}^{1} \Pi_{E+1}(h) d G(h)\right\} .
$$

Let $x=R_{E+1}$ in (A11) then by virtue of $\Pi_{E+1}\left(R_{E+1}\right)=0$, we obtain the asset Equation (33). If we use the wage Equation (30) in (25), we obtain, for $i=2, \ldots, E-1$ :

(A12) $\Pi_{E-i}(x)=\rho\left\{(1-\beta) y x-(1-\beta) r U_{E-(i+1) 0}+(1-\beta)\left[U_{E-i 0}-U_{E-(i+1) 0}\right]+\right.$

$$
\left.\lambda \int_{R_{E-(i-1)}}^{1} \Pi_{E-(i-1)}(h) d G(h)+(1-\lambda) \max \left\{0, \Pi_{E-(i-1)}(x)\right\}\right\} .
$$

If we use $x=R_{E-i}$ in (A12) and consider the reservation condition (32), we obtain the continuation value (34).

(ii) If we use $x=R_{E+1}$ in (A11) and solve the equation for $R_{E+1}$, considering the reservation condition (32), we get the job-destruction rule (35). Correspondingly, if we use $x=R_{E-i}$ in (A12) and solve for the reservation productivity $R_{E-i}$, we get the job-destruction-rule (36). 


\section{Appendix IV}

\section{A. Pool equations}

First we deal with the steady equations for the number of employed workers, $e_{E-i}, i=0, \ldots, E-1$, then we develop the steady state conditions for the job seekers, $u_{E-i T-j}, i=0, \ldots, E, j=i, \ldots, T$. The effects of the parameters of the labour market policy $[E, \gamma, T, b]$ on the equilibrium unemployment rate $u$ do not depend on whether the qualifying period $E$ is shorter or longer than the benefit duration $T$. For the sake of brevity, we represent the pool equations and the proofs for the case $E \leq T$. The simulations and results, Section 4, also take into account the case $E \geq T+1$.

\section{Employed Workers}

In the steady state, the following equations hold for the number of the employed workers with the qualifying counter $E-i$ and $i=0, \ldots, E-1$ :

(A13)

$$
e_{E-i}=\left\{\begin{array}{l}
{\left[1-\lambda G\left(R_{E+1}\right)\right] e_{E}+p \lambda G\left(R_{E+1}\right) e_{E}+\left[1-\lambda G\left(R_{E}\right)\right] e_{E-1}+} \\
\quad p \lambda G\left(R_{E}\right) e_{E-1}+p \sum_{m=0}^{1} \sum_{j=m}^{T} u_{E-m T-j}, \quad i=0 \\
\\
p \sum_{j=i+1}^{T} u_{E-(i+1) T-j}, \quad i=1, \ldots, E-2 \\
p \sum_{j=0}^{T-E} u_{0 T-(E+j)}, \quad i=E-1
\end{array}\right.
$$

Ad $i=0: e_{E}$ is the measure of the employed workers with a completed qualifying period. The inflow of $e_{E}$ consists first of workers with a productive job who are entitled to UB, $\left[1-\lambda G\left(R_{E+1}\right)\right] e_{E}$; second, workers entitled to UB who made a job-to-job transition belong to the inflow, $p \lambda G\left(R_{E+1}\right) e_{E}$; third, in the inflow are the workers of the pool $e_{E-1}$ who make a transition to $e_{E},\left[1-\lambda G\left(R_{E}\right)\right] e_{E-1}$, or who made a job-to-job transition to $e_{E}$, $p \lambda G\left(R_{E}\right) e_{E-1}$; and fourth, the successful job seekers $p \sum_{m=0}^{1} u_{E-m}$, where $u_{E-m} \equiv \sum_{j=m}^{T} u_{E-m T-j}$, with a qualifying counter equal to $E$ or $E-1$ belong also to the inflow of $e_{E}$. 
Ad $i=E-1$ : The inflow of the pool $e_{1}$ consists of successful job seekers whose qualifying counter is equal to zero because of the long unemployment, $p u_{0}$, where $u_{0} \equiv \sum_{j=0}^{T-E} u_{0 T-(E+j)}$.

\section{Job Seekers}

2.1 For the measure of job seekers with a completed qualifying period and a current spell of unemployment of length $j, u_{E T-j}$, the following holds in the steady state

$$
u_{E T-j}=\left\{\begin{array}{l}
(1-p) \lambda G\left(R_{E+1}\right) e_{E}, \quad j=0 \\
\gamma(1-p) u_{E T-(j-1)}, j=1, \ldots, T-1 . \\
\gamma(1-p)\left(u_{E 0}+u_{E 1}\right), \quad j=T
\end{array}\right.
$$

Ad $j=0: u_{E T}$ is the pool of the unemployed with a completed qualifying period and full entitlement to UB. The inflow to $u_{E T}$ consists of workers with a completed qualifying period who lost their job in the previous period and did not meet a vacancy during the last matching.

Ad $j=T$ : The third line of (A14) shows the inflow to the pool of job seekers with a completed qualifying period, but no residual claims to unemployment insurance, $u_{E 0}$. The inflow consists of job seekers from the pool $u_{E 0}+u_{E 1}$ who, although without a match, retain their qualifying points, an event, which has the probability $\gamma(1-p)$.

2.2 For the pool of job seekers with a current spell of unemployment of length $j$ and a qualifying counter equal to $E-i, u_{E-i T-j}$, the following steady state condition holds

$$
u_{E-i T-j}=\left\{\begin{array}{l}
(1-\gamma)(1-p) u_{E-(i-1) T-(j-1)}, \quad i=1, \ldots, E-1, j=i \\
(1-p)\left[\gamma u_{E-i T-(j-1)}+(1-\gamma) u_{E-(i-1) T-(j-1)}\right], \quad i=1, \ldots, E-1, \quad j=i+1, \ldots, T-1 \\
(1-p)\left[\lambda G\left(R_{E-(i-1)}\right) e_{E-i}+\gamma\left(u_{E-i 0}+u_{E-i 1}\right)+\right. \\
\left.(1-\gamma)\left(u_{E-(i-1) 0}+u_{E-(i-1) 1}\right)\right], \quad i=1, \ldots, E-1, \quad j=T
\end{array}\right.
$$

Ad $i=1, \ldots, E-1, j=i$ : Since $j \geq i, u_{E-i T-i}$ is the pool of job seekers which has the shortest current spell of unemployment of $j=i$ periods given the qualifying counter $E-i$. As the first line of (A15) illustrates, the inflow to $u_{E-i T-i}$ consists of unsuccessful job seekers who still belonged to the pool $u_{E-(i-1) T-(j-1)}$ in the previous period. ${ }^{8}$

8 In view of base period $F$, this transition corresponds to the transition of a job seeker with the qualifying counter $E-(i-1)$ who did not meet a vacancy and was employed $F$ periods ago. 
Ad $i=1, \ldots, E-1, j=T$ : The inflow to the pool $u_{E-i 0}$ is first composed of workers who lost their job because of an adverse shock and did not meet a vacancy during the subsequent matching, $(1-p) \lambda G\left(R_{E-(i-1)}\right) e_{E-i}$. Secondly, the fraction of the unsuccessful job seekers from pool $u_{E-i 0}+u_{E-i 1}$ makes a transition to $u_{E-i 0}$ who retain their qualifying points. ${ }^{9}$ Finally the fraction of unsuccessful job seekers from the pool $u_{E-(i-1) 0}+u_{E-(i-1) 1}$ who lose a qualifying point belong also to the inflow to $u_{E-i 0}$.

2.3 For job seekers with a current spell of unemployment of length $j \geq E$, whose qualifying counter is equal to zero, $u_{0 T-j}$, the following steady state conditions hold

$$
u_{0 T-j}=\left\{\begin{array}{l}
(1-\gamma)(1-p) u_{1 T-(E-1)}, j=E \\
(1-p)\left[u_{0 T-(j-1)}+(1-\gamma) u_{1 T-(j-1)}\right], j=E+1, \ldots, T-1 \\
(1-p)\left[u_{00}+u_{01}+(1-\gamma)\left(u_{10}+u_{11}\right)\right], j=T
\end{array}\right.
$$

Ad $j=T$ : The pool $u_{00}$ consists of job seekers who have neither qualifying points nor residual claims for unemployment insurance. The inflow to $u_{00}$ is composed of unsuccessful job seekers first from pool $u_{00}+u_{01}$ and second from pool $u_{10}+u_{11}$ who lose the last qualifying point at the transition.

\section{B. Conditional Probabilities $\mu_{E-i T-j}=u_{E-i T-j} / u$ (Lemmas A1 - A5)}

Next we present the Lemmas A1 - A4, to be used to develop the functional forms of the above pool equations and the fractions $\varepsilon_{E-i}\left(\theta, \Psi_{E}, R_{E+1}\right)$. Lemma A4 derives the conditional probabilities $\mu_{E-i T-j}$ to meet a job seeker with characteristics $[E-i, T-j]$ from the solutions of the pool equations.

\section{Lemmas $A 1-A 4$}

Lemma $A 1$ presents solutions of the difference Equations (A14) - (A16) for the different types of job seekers. To solve the equations, we use the conditional probability $a(\theta) \equiv \frac{(1-\gamma)[1-p(\theta)]}{p(\theta)+(1-\gamma)[1-p(\theta)]}$, which depends on the tightness $\theta$. A job seeker with qualifying counter $E-i$ makes a transition from his type-specific pool $u_{E-i} \equiv \sum_{j=i}^{T} u_{E-i T-j}$ either because his search was successful or because he did not meet a vacancy and loses a qualifying point. The first event occurs with the probability $p$, the second with the probability $(1-\gamma)(1-p)$. $a$ is the probability that a job seeker who makes a

9 These workers were unemployed $F$ periods ago. 
transition will not find a job and loses a qualifying point. $1-a$ is the probability that a job seeker who makes a transition will find a new job.

Lemma A1 (i) [Job Seekers]. 1. For the job seeker pool $u_{E-i T-j}$, with $i=0, \ldots, E-1$ and $j=i, \ldots, T-1$, the following is true:

$$
u_{E-i T-j}=\left(\begin{array}{c}
j \\
i
\end{array}\right)(1-\gamma)^{i}(1-p)^{j+1} \gamma^{j-i} \lambda G\left(R_{E+1}\right) e_{E} .
$$

2. For the job seeker pool $u_{E-i 0}$, with $i=1, \ldots, E-1$, we have:

(A18) $u_{E-i 0}=\frac{1-p}{1-\gamma(1-p)}\left[(1-p)^{T} \lambda G\left(R_{E+1}\right) e_{E} \sum_{k=0}^{i}\left(\begin{array}{l}T \\ k\end{array}\right) a^{i-k}(1-\gamma)^{k} \gamma^{T-k}+\sum_{k=1}^{i} a^{i-k} \lambda G\left(R_{E-(k-1)}\right) e_{E-k}\right]$.

3. For the pool $u_{E 0}$ we can prove:

$$
u_{E 0}=\frac{1-p}{1-\gamma(1-p)}(1-p)^{T} \gamma^{T} \lambda G\left(R_{E+1}\right) e_{E} .
$$

4. For the pool $u_{0 T-(E+j)}$, with $j=0, \ldots, T-(E+1)$, the following is the case:

$$
u_{0 T-(E+j)}=(1-p)^{E+j+1}(1-\gamma)^{E} \lambda G\left(R_{E+1}\right) e_{E} \sum_{k=0}^{j}\left(\begin{array}{c}
E-1+k \\
E-1
\end{array}\right) \gamma^{k}
$$

5. For the pool $u_{00}$ the following is true:

$$
\begin{aligned}
& u_{00}=\frac{1-p}{p} \sum_{k=0}^{E-1} a^{E-k} \lambda G\left(R_{E-(k-1)}\right) e_{E-k}- \\
& \frac{(1-p)^{E+1}}{p}(1-\gamma)^{E} \lambda G\left(R_{E+1}\right) e_{E} \sum_{j=0}^{T-E}\left(\begin{array}{c}
E-1+j \\
E-1
\end{array}\right)(1-p)^{j} \gamma^{j}\left[1-(1-p)^{T-(E+j)}\right]
\end{aligned}
$$

(ii) [Aggregate Pools]. 1. In the steady state, the aggregate pool $u_{E-i} \equiv \sum_{j=i}^{T} u_{E-i T-j}, i=1, \ldots, E-1$, is determined by

$$
u_{E-i}=\frac{1-p}{1-\gamma(1-p)} \sum_{k=0}^{i} a^{i-k} \lambda G\left(R_{E-(k-1)}\right) e_{E-k} .
$$

2. For the aggregate pool $u_{E} \equiv \sum_{j=0}^{T} u_{E T-j}$ the following is true

$$
u_{E}=\frac{1-p}{1-\gamma(1-p)} \lambda G\left(R_{E+1}\right) e_{E} .
$$

3. Finally for $u_{0} \equiv \sum_{j=0}^{T-E} u_{0 T-(E+j)}$ the following steady state equation holds:

$$
u_{0}=\frac{1-p}{p} \sum_{k=0}^{E-1} a^{E-k} \lambda G\left(R_{E-(k-1)}\right) e_{E-k} .
$$


Lemma A2 provides solutions of the difference Equations (A13) for the different types of employed workers. We use the following notation for the qualifying path: $\Psi_{E}=\left(R_{2}, \ldots, R_{E}\right)$.

Lemma A2 [Employed workers]. (i) For the pool of employed workers with the qualifying counter $E-i, i=1, \ldots, E-1$, the following holds:

$(\mathrm{A} 25)$

$$
e_{E-i}=\left\{\begin{array}{l}
\frac{a^{2}}{1-a(1-p) \lambda G\left(R_{E}\right)}(1-p) \lambda G\left(R_{E+1}\right) e_{E}, i=1 \\
\frac{a}{1-a(1-p) \lambda G\left(R_{E-(i-1)}\right)} e_{E-(i-1)}, i=2, \ldots, E-2 \\
\frac{\sum_{k=0}^{E-2} a^{E-k}(1-p) \lambda G\left(R_{E-(k-1)}\right) e_{E-k}}{1-a(1-p) \lambda G\left(R_{2}\right)}, i=E-1
\end{array}\right.
$$

(ii) By using the difference Equations (A25) we obtain:

$$
e_{E-i}=f_{E-i}\left(\theta, R_{E-i}, \ldots, R_{E}, R_{E+1}\right) e_{E}, i=1, \ldots E-1
$$

where for the frequencies $f_{E-i}, i=1, \ldots, E-2$, the following holds:

$$
f_{E-i}\left(\theta, R_{E-(i-1)}, \ldots, R_{E}, R_{E+1}\right) \equiv \frac{a(\theta)^{i+1}(1-p(\theta)) \lambda G\left(R_{E+1}\right)}{\prod_{k=0}^{i-1}\left[1-a(\theta)(1-p(\theta)) \lambda G\left(R_{E-k}\right)\right]}
$$

and for $f_{1}$ :

$$
f_{1}\left(\theta, \Psi_{E}, R_{E+1}\right) \equiv \frac{\sum_{k=0}^{E-2} a(\theta)^{E-k}(1-p(\theta)) \lambda G\left(R_{E-(k-1)}\right) f_{E-k}\left(\theta, \Psi_{E-(k-1)}, R_{E+1}\right)}{1-a(\theta)(1-p(\theta)) \lambda G\left(R_{2}\right)},
$$

with $f_{E} \equiv 1$.

With Lemma A2 we obtain the fractions $\varepsilon_{E-i}\left(\theta, \Psi_{E}, R_{E+1}\right)$, see Lemma A3, and the conditional probabilities $\mu_{E-i T-j}=u_{E-i T-j} / u$, see Lemma A4.

Lemma A3 [Fractions $\varepsilon_{E-i}$ ]. The fraction of employed workers with the qualifying counter $E-i$ is

$$
\varepsilon_{E-i}\left(\theta, \Psi_{E}, R_{E+1}\right)=\frac{f_{E-i}\left(\theta, \Psi_{E-(i-1)}, R_{E+1}\right)}{1+\sum_{k=1}^{E-1} f_{E-k}\left(\theta, \Psi_{E-(k-1)}, R_{E+1}\right)}, i=0, \ldots, E-1 .
$$


Lemma A4. For the conditional probabilities $\mu_{E-i T-j}=u_{E-i T-j} / u$, we obtain, with

$$
F\left(\theta, \Psi_{E}, R_{E+1}\right) \equiv(1-p(\theta)) \sum_{i=0}^{E-1} f_{E-i}\left(\theta, \Psi_{E-(i-1)}, R_{E+1}\right) \lambda G\left(R_{E-(i-1)}\right),
$$

the following:

$$
\begin{aligned}
\text { (A30) } & \mu_{E-i T-j}=\left(\begin{array}{c}
j \\
i
\end{array}\right)(1-\gamma)^{i}(1-p)^{j+1} \gamma^{j-i} \lambda G\left(R_{E+1}\right) p F\left(\theta, \Psi_{E}, R_{E+1}\right), i=0, \ldots, E-1, \\
& j=i, \ldots, T-1 .
\end{aligned}
$$

(A31) $\quad \mu_{E 0}=(1-a)(1-p)^{T+1} \gamma^{T} \lambda G\left(R_{E+1}\right) F\left(\theta, \Psi_{E}, R_{E+1}\right)$.

(A32) $\quad \mu_{E-i 0}=(1-a) F\left(\theta, \Psi_{E}, R_{E+1}\right)\left[(1-p)^{T+1} \lambda G\left(R_{E+1}\right) \sum_{k=0}^{i}\left(\begin{array}{l}T \\ k\end{array}\right) a^{i-k}(1-\gamma)^{k} \gamma^{T-k}+\right.$

$$
\left.(1-p) \sum_{k=1}^{i} a^{i-k} \lambda G\left(R_{E-(k-1)}\right) f_{E-k}\right], \quad i=1, \ldots, E-1
$$

(A33) $\quad \mu_{0 T-(E+j)}=(1-p)^{E+j+1}(1-\gamma)^{E} \lambda G\left(R_{E+1}\right) p F\left(\theta, \Psi_{E}, R_{E+1}\right) \sum_{k=0}^{j}\left(\begin{array}{c}E-1+k \\ E-1\end{array}\right) \gamma^{k}$, $j=0, \ldots, T-(E+1)$.

(A34) $\quad \mu_{00}=F\left(\theta, \Psi_{E}, R_{E+1}\right)\left[(1-p) \sum_{k=1}^{i} a^{i-k} \lambda G\left(R_{E-(k-1)}\right) f_{E-k}-\right.$

$$
\left.(1-p)^{E+1}(1-\gamma)^{E} \lambda G\left(R_{E+1}\right) \sum_{j=0}^{T-E}\left(\begin{array}{c}
E-1+j \\
E-1
\end{array}\right)(1-p)^{j} \gamma^{j}\left[1-(1-p)^{T-(E+j)}\right]\right],
$$

where $f_{E-k}=f_{E-k}\left(\theta, \Psi_{E-k}, R_{E+1}\right)$.

2. Proofs of the Lemmas $A 1-A 4$

Proof of Lemma A1. (i) [J ob SeEkers] 1. When $j=i$, in view of (A15) the statement follows directly from the equation $u_{E-i T-i}=(1-p)(1-\gamma) u_{E-(i-1) T-(i-1)}$ and (A14). Now, let $j>i$, then by virtue of (A15), we get the following results by induction over $j$ : 


$$
\begin{aligned}
u_{E-i T-j} & =(1-p)\left[\gamma u_{E-i T-(j-1)}+(1-\gamma) u_{E-(i-1) T-(j-1)}\right] \\
& =(1-p)\left[\gamma\left(\begin{array}{c}
j-1 \\
i
\end{array}\right)(1-\gamma)^{i}(1-p)^{(j-1)+1} \gamma^{(j-1)-i} \lambda G\left(R_{E+1}\right) e_{E}+\right. \\
& =\left[\left(\begin{array}{c}
j-1 \\
i
\end{array}\right)+\left(\begin{array}{c}
j-1 \\
i-1
\end{array}\right)\right](1-\gamma)^{i}(1-p)^{j+1} \gamma^{j-i} \lambda G\left(R_{E+1}\right) e_{E} \\
& =\left(\begin{array}{c}
j-1 \\
i
\end{array}\right)(1-\gamma)^{i}(1-p)^{j+1} \gamma^{j-i} \lambda G\left(R_{E+1}\right) e_{E} .
\end{aligned}
$$

2. With $(A 15)$,

$$
\begin{aligned}
u_{E-i 0} & =(1-p)\left[\lambda G\left(R_{E-(i-1)}\right) e_{E-i}+\gamma\left(u_{E-i 0}+u_{E-i 1}\right)+(1-\gamma)\left(u_{E-(i-1) 0}+u_{E-(i-1) 1}\right)\right] \\
& =\frac{(1-p)}{1-\gamma(1-p)}\left[\lambda G\left(R_{E-(i-1)}\right) e_{E-i}+\gamma u_{E-i 1}+(1-\gamma)\left(u_{E-(i-1) 0}+u_{E-(i-1) 1}\right)\right] .
\end{aligned}
$$

We eliminate $u_{E-i 1}$ and $u_{E-(i-1) 1}$ using $(\mathrm{A} 17)$, and replace $u_{E-(i-1) 0}$ by induction over $i$ taking into account that $(1-\gamma) \frac{(1-p)}{1-\gamma(1-p)}=a$, to arrive at:

$$
\begin{aligned}
u_{E-i 0}= & \frac{(1-p)}{1-\gamma(1-p)}\left[\lambda G\left(R_{E-(i-1)}\right) e_{E-i}+\left(\begin{array}{c}
T-1 \\
i
\end{array}\right)(1-\gamma)^{i}(1-p)^{T} \gamma^{T-i} \lambda G\left(R_{E+1}\right) e_{E}+\right. \\
& (1-p)^{T} \lambda G\left(R_{E+1}\right) e_{E} \sum_{k=0}^{i-1}\left(\begin{array}{c}
T \\
k
\end{array}\right) a^{i-k}(1-\gamma)^{k} \gamma^{T-k}+\sum_{k=1}^{i-1} a^{i-k} \lambda G\left(R_{E-(k-1)}\right) e_{E-k}+ \\
& \left.\left(\begin{array}{c}
T-1 \\
i-1
\end{array}\right)(1-\gamma)^{i}(1-p)^{T} \gamma^{T-i} \lambda G\left(R_{E+1}\right) e_{E}\right] .
\end{aligned}
$$

Collecting terms it follows:

$$
\begin{aligned}
u_{E-i 0}= & \frac{(1-p)}{1-\gamma(1-p)}\left[\sum_{k=1}^{i} a^{i-k} \lambda G\left(R_{E-(k-1)}\right) e_{E-k}+\right. \\
& \left.(1-p)^{T} \lambda G\left(R_{E+1}\right) e_{E}\left[(1-\gamma)^{i} \gamma^{T-i}\left[\left(\begin{array}{c}
T-1 \\
i-1
\end{array}\right)+\left(\begin{array}{c}
T-1 \\
i
\end{array}\right)\right]+\sum_{k=0}^{i-1}\left(\begin{array}{l}
T \\
k
\end{array}\right) a^{i-k}(1-\gamma)^{k} \gamma^{T-k}\right]\right] \\
= & \frac{(1-p)}{1-\gamma(1-p)}\left[\sum_{k=1}^{i} a^{i-k} \lambda G\left(R_{E-(k-1)}\right) e_{E-k}+(1-p)^{T} \lambda G\left(R_{E+1}\right) e_{E} \sum_{k=0}^{i}\left(\begin{array}{l}
T \\
k
\end{array}\right) a^{i-k}(1-\gamma)^{k} \gamma^{T-k}\right] .
\end{aligned}
$$

3. With (A14) $u_{E 0}=\gamma(1-p)\left(u_{E 0}+u_{E 1}\right)$ results. If we eliminate $u_{E 1}$ with (A17) and solve for $u_{E 0}$, the statement follows. 
4. From (A16) $u_{0 T-(E+j)}=(1-p)\left[u_{0 T-(E+j-1)}+(1-\gamma) u_{1 T-(E+j-1)}\right]$. If we eliminate $u_{1 T-(E+j-1)}$ with (A17) and $u_{0 T-(E+j-1)}$ by induction over $j$, the statement follows:

$$
\begin{aligned}
u_{0 T-(E+j)} & =\left[\sum_{k=0}^{j-1}\left(\begin{array}{c}
E-1+k \\
E-1
\end{array}\right) \gamma^{k}+\left(\begin{array}{c}
E+j-1 \\
E-1
\end{array}\right) \gamma^{j}\right](1-p)^{E+j+1}(1-\gamma)^{E} \lambda G\left(R_{E+1}\right) e_{E} \\
& =(1-p)^{E+j+1}(1-\gamma)^{E} \lambda G\left(R_{E+1}\right) e_{E} \sum_{k=0}^{j}\left(\begin{array}{c}
E-1+k \\
E-1
\end{array}\right) \gamma^{k} .
\end{aligned}
$$

5. From (A16): $u_{00}=\frac{(1-p)}{p}\left[u_{01}+(1-\gamma)\left(u_{10}+u_{11}\right)\right]$. Replace $u_{01}$ with (A20), $u_{10}$ with (A18) and $u_{11}$ with (A17), to get:

$$
\begin{aligned}
u_{00}=\frac{(1-p)}{p}\left[\sum_{k=1}^{E-1} a^{E-k} \lambda G\left(R_{E-(k-1)}\right) e_{E-k}+\right. \\
\left.(1-\gamma)^{E}(1-p)^{T} \lambda G\left(R_{E+1}\right) e_{E}\left[\sum_{j=0}^{T-E}\left(\begin{array}{c}
E-1+j \\
E-1
\end{array}\right) \gamma^{j}+\sum_{j=0}^{E-1}\left(\begin{array}{c}
T \\
j
\end{array}\right) a^{E-j}(1-\gamma)^{j-E} \gamma^{T-j}\right]\right] \\
=\frac{(1-p)}{p}\left[\sum_{k=1}^{E-1} a^{E-k} \lambda G\left(R_{E-(k-1)}\right) e_{E-k}+\lambda G\left(R_{E+1}\right) e_{E}\left[(1-\gamma)^{E}(1-p)^{T} \sum_{j=0}^{T-E}\left(\begin{array}{c}
E-1+j \\
E-1
\end{array}\right) \gamma^{j}+\right.\right. \\
\left.\left.a^{E} \sum_{j=0}^{E-1}\left(\begin{array}{c}
T \\
j
\end{array}\right)[1-\gamma(1-p)]^{j}(1-p)^{T-j} \gamma^{T-j}\right]\right]
\end{aligned}
$$

In view of Lemma $\mathrm{A} 5$ (i) below and $\left(\begin{array}{c}E-1+j \\ j\end{array}\right)=\left(\begin{array}{c}E-1+j \\ E-1\end{array}\right)$, we can write:

$$
\begin{aligned}
& u_{00}= \frac{(1-p)}{p}\left[\sum_{k=1}^{E-1} a^{E-k} \lambda G\left(R_{E-(k-1)}\right) e_{E-k}+\lambda G\left(R_{E+1}\right) e_{E}\left[(1-\gamma)^{E}(1-p)^{T} \sum_{j=0}^{T-E}\left(\begin{array}{c}
E-1+j \\
E-1
\end{array}\right) \gamma^{j}+\right.\right. \\
&\left.\left.a^{E}\left[1-[1-\gamma(1-p)]^{E} \sum_{j=0}^{T-E}\left(\begin{array}{c}
E-1+j \\
E-1
\end{array}\right)(1-p)^{j} \gamma^{j}\right]\right]\right] \\
&=\frac{(1-p)}{p}\left[\sum_{k=0}^{E-1} a^{E-k} \lambda G\left(R_{E-(k-1)}\right) e_{E-k}-\right. \\
&\left.(1-p)^{E}(1-\gamma)^{E} \lambda G\left(R_{E+1}\right) e_{E} \sum_{j=0}^{T-E}\left(\begin{array}{c}
E-1+j \\
E-1
\end{array}\right)(1-p)^{j} \gamma^{j}\left[1-(1-p)^{T-(E+j)}\right]\right] .
\end{aligned}
$$

(ii) [Aggregate Pools]. The equations for the aggregate pools (A22) (A24) can be derived from the steady state conditions or, as below, from the pool Equations (A17) - (A21).

1. For the pool $u_{E-i} \equiv \sum_{j=i}^{T} u_{E-i T-j}$, in view of $u_{E-i}=u_{E-i 0}+\sum_{j=i}^{T-1} u_{E-i T-j}$, the following results from $(\mathrm{A} 17)$ and $(\mathrm{A} 18)$ : 


$$
\begin{aligned}
& u_{E-i}= \frac{1-p}{1-\gamma(1-p)} \sum_{k=1}^{i} a^{i-k} \lambda G\left(R_{E-(k-1)}\right) e_{E-k}+ \\
&(1-p) \lambda G\left(R_{E+1}\right) e_{E}\left[(1-\gamma)^{i} \sum_{j=i}^{T-1}\left(\begin{array}{l}
j \\
i
\end{array}\right)(1-p)^{j} \gamma^{j-i}+\frac{(1-p)^{T}}{1-\gamma(1-p)} \sum_{k=0}^{i}\left(\begin{array}{l}
T \\
k
\end{array}\right) a^{i-k}(1-\gamma)^{k} \gamma^{T-k}\right] \\
&= \frac{1-p}{1-\gamma(1-p)} \sum_{k=1}^{i} a^{i-k} \lambda G\left(R_{E-(k-1)}\right) e_{E-k}+ \\
& \frac{(1-p)}{1-\gamma(1-p)} a^{i} \lambda G\left(R_{E+1}\right) e_{E}\left[[1-\gamma(1-p)]^{j+1} \sum_{j=i}^{T-1}\left(\begin{array}{l}
j \\
i
\end{array}\right)(1-p)^{j-i} \gamma^{j-i}+\sum_{k=0}^{i}\left(\begin{array}{l}
T \\
k
\end{array}\right)[1-\gamma(1-p)]^{k}(1-p)^{T-k} \gamma^{T-k}\right]
\end{aligned}
$$

so that, in view of Lemma A5 (i) below, the statement follows.

2. For the pool $u_{E} \equiv \sum_{j=0}^{T} u_{E T-j}$, we can write $u_{E}=u_{E 0}+\sum_{j=0}^{T-1} u_{E T-j}$, so that the statement from (A17) for $i=0$ and (A19) follows.

3. For the pool $u_{0} \equiv \sum_{j=0}^{T-E} u_{0 T-(E+j)}$, we can write $u_{0}=u_{00}+\sum_{j=0}^{T-(E+1)} u_{0 T-(E+j)}$, so that with (A20) and Lemma A5 (ii) below, we obtain the following equation:

$$
\begin{aligned}
u_{0} & =u_{00}+(1-p)^{E+1}(1-\gamma)^{E} \lambda G\left(R_{E+1}\right) e_{E} \sum_{j=0}^{T-(E+1)}(1-p)^{j} \sum_{k=0}^{j}\left(\begin{array}{c}
E-1+k \\
E-1
\end{array}\right) \gamma^{k} \\
& =u_{00}+(1-p)^{E+1}(1-\gamma)^{E} \lambda G\left(R_{E+1}\right) e_{E} \sum_{j=0}^{T-(E+1)}\left(\begin{array}{c}
E-1+j \\
E-1
\end{array}\right)(1-p)^{j} \gamma^{j} \frac{\left[1-(1-p)^{T-(E+j)}\right]}{p} .
\end{aligned}
$$

If we replace $u_{00}$ using (A21), the proposition follows.

Proof of Lemma A2. (i) 1. For $e_{E}$, we get with $i=0$ from (A13):

$e_{E}=\left[1-\lambda G\left(R_{E+1}\right)\right] e_{E}+p \lambda G\left(R_{E+1}\right) e_{E}+\left[1-\lambda G\left(R_{E}\right)\right] e_{E-1}+p \lambda G\left(R_{E}\right) e_{E-1}+p\left[u_{E}+u_{E-1}\right]$. If we replace $u_{E}+u_{E-1}$ using (A22) and (A23) and solve for $e_{E-1}$, we obtain the first line of (A25).

2. For $i=1, \ldots, E-2$, we obtain the following from (A13), in view of (A22):

$$
\begin{aligned}
e_{E-i} & =\left[1-\lambda G\left(R_{E-i}\right)\right] e_{E-(i+1)}+p \lambda G\left(R_{E-i}\right) e_{E-(i+1)}+p u_{E-(i+1)} \\
& =\left[1-(1-p) \lambda G\left(R_{E-i}\right)\right] e_{E-(i+1)}+(1-a)(1-p) \sum_{k=0}^{i+1} a^{i+1-k} \lambda G\left(R_{E-(k-1)}\right) e_{E-k} \\
& =\left[1-a(1-p) \lambda G\left(R_{E-i}\right)\right] e_{E-(i+1)}+a(1-a)(1-p) \sum_{k=0}^{i} a^{i-k} \lambda G\left(R_{E-(k-1)}\right) e_{E-k} \\
& =\left[1-a(1-p) \lambda G\left(R_{E-i}\right)\right] e_{E-(i+1)}+a p u_{E-i} \\
& =\left[1-a(1-p) \lambda G\left(R_{E-i}\right)\right] e_{E-(i+1)}+a\left[e_{E-(i-1)}-\left[1-(1-p) \lambda G\left(R_{E-(i-1)}\right)\right] e_{E-i}\right],
\end{aligned}
$$

where we make use of (A13) to derive the last equation. Rearranging terms gives:

$$
a\left(e_{E-i}-e_{E-(i-1)}\right)+\left[1-a(1-p) \lambda G\left(R_{E-(i-1)}\right)\right] e_{E-i}=\left[1-a(1-p) \lambda G\left(R_{E-i}\right)\right] e_{E-(i+1)} .
$$


By induction over $i$, we get: $\left[1-a(1-p) \lambda G\left(R_{E-(i-1)}\right)\right] e_{E-i}=a e_{E-(i-1)}$. Replacing the LHS and solving for $e_{E-(i+1)}$ gives the second line of (A25).

3. For $e_{1}$ and $i=E-1, e_{1}=p u_{0}$ results from (A13), with (A24) we get: $e_{1}=(1-p) \sum_{k=0}^{E-1} a^{E-k} \lambda G\left(R_{E-(k-1)}\right) e_{E-k}$. From the last equation, it follows that $e_{1}=a(1-p) \lambda G\left(R_{2}\right) e_{1}+(1-p) \sum_{k=0}^{E-2} a^{E-k} \lambda G\left(R_{E-(k-1)}\right) e_{E-k}$. If we solve for $e_{1}$, we get the last line of (A17).

(ii) The expression (A26) is derived from (A13) by virtue of (A27) and (A28).

Proof of Lemma A3. In view of (A26) we can write $\varepsilon_{E-i}=f_{E-i} \varepsilon_{E}$. From this, we can conclude that $\sum_{i=1}^{E-1} \varepsilon_{E-i}=1-\varepsilon_{E}=\varepsilon_{E} \sum_{i=1}^{E-1} f_{E-i}$, so that

$$
\varepsilon_{E}\left(\theta, \Psi_{E}, R_{E+1}\right)=\frac{1}{1+\sum_{i=1}^{E-1} f_{E-i}\left(\theta, \Psi_{E-(i-1)}, R_{E+1}\right)} .
$$

Inserting this expression into $\varepsilon_{E-i}=f_{E-i} \varepsilon_{E}$ gives the statement (A29).

Proof of Lemma A4. The conditional probabilities $\mu_{E-i T-j}$ - that an applicant has $E-i$ qualifying points and a residual claim to the UB $b$ of $T-j$ periods - directly follow from Lemma A1, where we make use of Lemma A5 (i) below.

\section{Lemmas $A 5$}

Lemma A5. (i) Let $T \geq i+1 \geq 1$, then the following equation holds:

(A27) $1=\sum_{j=0}^{i}\left(\begin{array}{l}T \\ j\end{array}\right)[1-\gamma(1-p)]^{j}(1-p)^{T-j} \gamma^{T-j}+[1-\gamma(1-p)]^{j+1} \sum_{j=0}^{T-(i+1)}\left(\begin{array}{c}i+j \\ j\end{array}\right)(1-p)^{j} \gamma^{j}$.

(ii) Let $T \geq E+1$, then we can prove:

(A28) $\sum_{j=0}^{T-(E+1)}(1-p)^{j} \sum_{k=0}^{j}\left(\begin{array}{c}E-1+k \\ E-1\end{array}\right) \gamma^{k}=\sum_{j=0}^{T-(E+1)}\left(\begin{array}{c}E-1+j \\ E-1\end{array}\right)(1-p)^{j} \gamma^{j} \frac{\left[1-(1-p)^{T-(E+j)}\right]}{p}$.

Proof of Lemma A5. (i) 1 . Let $i=0$, then clearly $(1-p)^{T} \gamma^{T}+[1-\gamma(1-p)] \sum_{j=0}^{T-1}(1-p)^{j} \gamma^{j}=1$ holds.

2. Assume the statement is true for $i$, then for $i+1$ and $T \geq i+2$ with $R H S(T) \equiv \sum_{j=0}^{i+1}\left(\begin{array}{c}T \\ j\end{array}\right)[1-\gamma(1-p)]^{j}(1-p)^{T-j} \gamma^{T-j}+[1-\gamma(1-p)]^{i+2} \sum_{j=0}^{T-(i+2)}\left(\begin{array}{c}i+1+j \\ j\end{array}\right)(1-p)^{j} \gamma^{j}$ it follows that 


$$
\begin{aligned}
& \operatorname{RHS}(T)= 1+[1-\gamma(1-p)]^{i+1}\left[\left(\begin{array}{c}
T \\
i+1
\end{array}\right)(1-p)^{T-(i+1)} \gamma^{T-(i+1)}+\right. \\
& {\left.[1-\gamma(1-p)] \sum_{j=0}^{T-(i+2)}\left(\begin{array}{c}
i+1+j \\
i+1
\end{array}\right)(1-p)^{j} \gamma^{j}-\sum_{j=0}^{T-(i+1)}\left(\begin{array}{c}
i+j \\
i
\end{array}\right)(1-p)^{j} \gamma^{j}\right] } \\
&= 1+[1-\gamma(1-p)]^{i+1}\left[(1-p)^{T-(i+1)} \gamma^{T-(i+1)}\left[\left(\begin{array}{c}
T \\
i+1
\end{array}\right)-\left(\begin{array}{c}
T-1 \\
i
\end{array}\right)\right]+\right. \\
&\left.\sum_{j=0}^{T-(i+2)}(1-p)^{j} \gamma^{j}\left[[1-\gamma(1-p)]\left(\begin{array}{c}
i+1+j \\
i+1
\end{array}\right)-\left(\begin{array}{c}
i+j \\
i
\end{array}\right)\right]\right]
\end{aligned}
$$

The second summand in the above equation is equal to zero! We prove this statement by induction over the benefit duration $T \geq i+2$. Clearly, for $T=i+2, \operatorname{RHS}(i+2)=1$ holds. For the conclusion from $T$ to $T+1$, in view of the induction hypothesis, it then holds that:

$$
\begin{aligned}
& \operatorname{RHS}(T+1)=1+[1-\gamma(1-p)]^{i+1}\left[(1-p)^{T-i} \gamma^{T-i}\left[\left(\begin{array}{c}
T \\
i+1
\end{array}\right) \frac{T+1}{T-i}-\left(\begin{array}{c}
T-1 \\
i
\end{array}\right) \frac{T}{T-i}\right]+\right. \\
& \left.\sum_{j=0}^{T-(i+2)}(1-p)^{j} \gamma^{j}\left[[1-\gamma(1-p)]\left(\begin{array}{c}
i+1+j \\
i+1
\end{array}\right)-\left(\begin{array}{c}
i+j \\
i
\end{array}\right)\right]+(1-p)^{T-(i+1)} \gamma^{T-(i+1)}\left[[1-\gamma(1-p)]\left(\begin{array}{c}
T \\
i+1
\end{array}\right)-\left(\begin{array}{c}
T-1 \\
i
\end{array}\right)\right]\right] \\
& =1+[1-\gamma(1-p)]^{i+1}\left[(1-p)^{T-i} \gamma^{T-i}\left[\left(\begin{array}{c}
T \\
i+1
\end{array}\right) \frac{T+1}{T-i}-\left(\begin{array}{c}
T-1 \\
i
\end{array}\right) \frac{T}{T-i}\right]-(1-p)^{T-i} \gamma^{T-i}\left(\begin{array}{c}
T \\
i+1
\end{array}\right)\right] \\
& =1 \text {. }
\end{aligned}
$$

(ii) 1. If $T=E+1$, then $R H S(T)=L H S(T)=1$ is true. 2. For the conclusion from $T$ to $T+1$ we develop the RHS of the Equation (A28):

$$
\begin{aligned}
& R H S(T+1) \equiv \sum_{j=0}^{T-E}\left(\begin{array}{c}
E-1+j \\
E-1
\end{array}\right)(1-p)^{j} \gamma^{j} \frac{\left[1-(1-p)(1-p)^{T-(E+j)}\right]}{p} \\
& =\sum_{j=0}^{T-(E+1)}\left(\begin{array}{c}
E-1+j \\
E-1
\end{array}\right)(1-p)^{j} \gamma^{j} \frac{\left[1-(1-p)^{T-(E+j)}\right]}{p}+\sum_{j=0}^{T-(E+1)}\left(\begin{array}{c}
E-1+j \\
E-1
\end{array}\right)(1-p)^{j} \gamma^{j}(1-p)^{T-(E+j)}+ \\
& \left(\begin{array}{c}
T-1 \\
E-1
\end{array}\right)(1-p)^{T-E} \gamma^{T-E} \\
& =\operatorname{LHS}(T)+(1-p)^{T-E}\left[\sum_{j=0}^{T-(E+1)}\left(\begin{array}{c}
E-1+j \\
E-1
\end{array}\right) \gamma^{j}+\left(\begin{array}{c}
T-1 \\
E-1
\end{array}\right) \gamma^{T-E}\right] \\
& =\operatorname{LHS}(T+1) .
\end{aligned}
$$

\section{Reservation I ncome and Rents (Lemma A6)}

With Lemma A6 we convert the guarantee income of the workers and the qualifying rents into expressions which depend on the model parameters, the tightness of the labor market and the asset values of the occupied jobs. 
Lemma A6 (i) [Reservation Income]. 1. The reservation income of a job seeker who neither owns qualifying points nor claims for unemployment benefits is:

$$
r U_{00}=z+\frac{\beta p}{(1-\beta)(1-p)} \Pi_{1}(1) \rho^{-1}
$$

2. The value of a job seeker who does not have qualifying points, but still has claims to UB after $j=E, \ldots, T-1$ periods of unemployment is:

$$
U_{0 T-j}=U_{00}+b \sum_{k=1}^{T-j} d^{k}
$$

where $d(\theta) \equiv \frac{\rho[1-p(\theta)]}{1-p(\theta)(1-\beta)}<1$.

3. For the reservation income of an insider with a qualifying counter equal to $E-i, i=1, \ldots, E-1$, the following is true

$$
\begin{aligned}
& \text { (A39) } r U_{E-i 0}=z+\frac{\beta p}{(1-\beta)(1-p)} \tau^{E-i} \Pi_{1}(1) \rho^{-1}+\frac{\beta p}{(1-\beta)(1-p)(1-\rho \gamma)} \sum_{k=0}^{E-i-1} \tau^{k} r \Pi_{E-(i+k-1)}(1) \text {, } \\
& \text { where } \tau \equiv \frac{\rho(1-\gamma)}{1-\rho \gamma}<1 .
\end{aligned}
$$

4. The value of a job seeker with a current spell of unemployment of length $j=i, \ldots, T-1$ and $E-i$ qualifying points, $i=1, \ldots, E-1$, is:

$$
U_{E-i T-j}=U_{E-i 0}+b \sum_{k=1}^{T-j} d^{k} \text {. }
$$

5. For the reservation income of an insider with a completed qualifying period we have

$$
\begin{aligned}
& r U_{E T}=\frac{(1-\rho)(1-d \gamma)}{1-\rho \gamma} \frac{1-d^{T}}{1-d} b+z+\frac{\beta p}{(1-\beta)(1-p)} \tau^{E} \Pi_{1}(1) \rho^{-1}+ \\
& \frac{\beta p}{(1-\beta)(1-p)(1-\rho \gamma)} \sum_{k=0}^{E-1} \tau^{k} r \Pi_{E-(k-1)}(1)
\end{aligned}
$$

6. A job seeker with a completed qualifying period and residual claims to UB over $T-j$ periods, $j=1, \ldots, T$, has the value:

$$
U_{E T-j}=U_{E T}-b \sum_{k=T-(j-1)}^{T} d^{k}
$$

(ii) [Rents]. 1. From (A39) we get the qualifying rent for a match that makes a transition from $e_{E-(i+1)}$ to $e_{E-i}$ with:

(A43) $U_{E-i 0}-U_{E-(i+1) 0}=\frac{\beta p}{(1-\beta)(1-p)(1-\rho \gamma)} \sum_{k=0}^{E-(i+1)} \tau^{k}\left[\Pi_{E-(i+k-1)}(1)-\Pi_{E-(i+k)}(1)\right]$. 
2. Lemma 4, Equation (31), shows that for two workers with a completed qualifying period - one is an outsider, the other an insider -, the outsider has the weaker bargaining position. The side payment he must accept is given by (A42)

$$
U_{E T}-U_{E T-j}=b \sum_{k=T-(j-1)}^{T} d^{k}
$$

3. If we compare two workers with $E-i$ qualifying points - one is an outsider with a residual benefit duration of $T-j$ periods, the other is an insider -, then the outsider is better off, (see Lemma 4, Equation (31)), because he receives a wage bonus for which, with (A40):

$$
U_{E-i T-j}-U_{E-i 0}=b \sum_{k=1}^{T-j} d^{k} .
$$

Proof of Lemma A6. (i) 1. The statement follows with $i=E, j=T$ from the asset Equations (A6), (A8) and the sharing rule (A5).

2. Assume $i=E$ and $j=E, \ldots, T-1$ then from the asset Equations (A6), (A8) and the sharing rule (A5) we get:

$$
U_{0 T-j}=\frac{\beta p}{(1-\beta)[1-(1-\beta) p]} \Pi_{1}(1)+\frac{\beta p}{1-(1-\beta) p} U_{00}+d\left[z+b+U_{0 T-(j+1)}\right] .
$$

Replace $\Pi_{1}(1)$ using (A37), and solve the difference equation to derive the statement.

3. From the asset Equation (A8), the sharing rule (27) and the Equation (A6) for the initial value of a filled job, we get

$$
U_{E-i 0}=\frac{\beta p}{(1-\beta)(1-p)(1-\rho \gamma)} \Pi_{E-(i-1)}(1)+\frac{\rho}{1-\rho \gamma}\left[z+(1-\gamma) U_{E-(i+1) 0}\right] .
$$

Solve the difference equation, replace $U_{00}$ with Equation (A37) and the statement follows.

4. With the asset Equation (A8), the sharing rule (A5) and the initial value of a filled job (A6) we obtain the following difference equation in the benefit duration $T-j$ :

$$
\begin{aligned}
U_{E-i T-j}=\frac{\beta p}{(1-\beta)[1-p(1-\beta)]}\left[\begin{array}{l}
{\left[\Pi_{E-(i-1)}(1)+(1-\beta) U_{E-i 0}\right]+} \\
d\left[z+b+\gamma U_{E-i T-(j+1)}+(1-\gamma) U_{E-(i+1) T-(j+1)}\right]
\end{array}\right.
\end{aligned}
$$

First, we show that the proposition holds for $T-j=1$. For $T-j=1$, we can derive from (A46) that

$$
\begin{aligned}
& U_{E-i 1}=\frac{\beta p}{(1-\beta)[1-p(1-\beta)]}\left[\Pi_{E-(i-1)}(1)+(1-\beta)\right.\left.U_{E-i 0}\right]+ \\
& d\left[z+b+\gamma U_{E-i 0}+(1-\gamma) U_{E-(i+1) 0}\right]
\end{aligned}
$$


If we replace $U_{E-(i+1) 0}$ with $(A 39)$, we get:

$$
\begin{aligned}
U_{E-i 1}=d[b+ & \left.\left(1+\frac{\rho(1-\gamma)}{1-\rho}\right) z+\left(\gamma+\frac{\beta p}{\rho(1-p)}\right) U_{E-i 0}\right]+ \\
& \frac{d(1-\rho \gamma)}{1-\rho}\left[\frac{\beta p}{(1-\beta)(1-p)} \tau^{E-i} \Pi_{1}(1) \rho^{-1}+\frac{\beta p}{(1-\beta)(1-p)(1-\rho \gamma)} \sum_{k=0}^{E-i-1} \tau^{k} r \Pi_{E-(i+k-1)}(1)\right]
\end{aligned}
$$

If we substitute the expression in the last brackets with (A39) by $r U_{E-i 0}-z$ and rearrange, we obtain the statement: $U_{E-i 1}=U_{E-i 0}+d b$. For the conclusion from $T-j$ to $T-(j-1)$ we eliminate $U_{E-i T-j}$ and $U_{E-(i+1) T-j}$ in (A46) with (A40) and obtain $U_{E-i T-(j-1)}=U_{E-i 0}+b \sum_{k=1}^{T-(j-1)} d^{k}$.

5. With (A8), (A6) and the sharing rule (14), we obtain the following equation for the guarantee value of an insider with a completed qualifying period, $U_{E T}$ :

$$
U_{E T}=\frac{\beta p}{(1-\beta)(1-p)} \Pi_{E+1}(1)+\rho\left[z+b+\gamma U_{E T-1}+(1-\gamma) U_{E-1 T-1}\right]
$$

To solve the difference equation, we need to know the guarantee value of a job seeker with a completed qualifying period and an unemployment spell of one period, $U_{E T-1}$. The value $U_{E-1 T-1}$ results from (A40).

With $(A 8),(A 6)$, the sharing rule $(A 5)$ and the wage Equation (31) we get:

$$
\begin{array}{r}
U_{E T-j}=\frac{\beta p}{(1-\beta)[1-p(1-\beta)]}\left[\Pi_{E+1}(1)+(1-\beta) U_{E T}\right]+ \\
d\left[z+b+\gamma U_{E T-(j+1)}+(1-\gamma) U_{E-1 T-(j+1)}\right] .
\end{array}
$$

Solve the difference Equation (A48) to obtain:

(A49)

$$
\begin{gathered}
U_{E T-j}=\frac{\beta p}{(1-\beta)[1-p(1-\beta)]} \frac{1-(d \gamma)^{T-j}}{1-d \gamma}\left[\Pi_{E+1}(1)+(1-\beta) U_{E T}\right]+\frac{1-(d \gamma)^{T-j}}{1-d \gamma} d(z+b)+ \\
(d \gamma)^{T-j} U_{E 0}+\frac{1-\gamma}{\gamma} \sum_{k=1}^{T-j}(d \gamma)^{k} U_{E-1 T-(j+k)}
\end{gathered}
$$

For $U_{E 0}$, we get from $(\mathrm{A} 8),(\mathrm{A} 6)$, the sharing rule $(\mathrm{A} 5)$ and the wage Equation (31):

$$
\begin{aligned}
U_{E 0}=\frac{\beta p}{(1-\beta)[(1-p)(1-\rho \gamma)+\beta p]}\left[\Pi_{E+1}(1)+(1-\beta) U_{E T}\right]+ \\
\frac{\rho(1-p)}{(1-p)(1-\rho \gamma)+\beta p}\left[z+(1-\gamma) U_{E-10}\right] .
\end{aligned}
$$


Insert (A50) and (A47) in (A49), to obtain the following equation for $j=1$ :

(A51)

$$
\begin{gathered}
U_{E T-1}+(1-\gamma) U_{E-1 T-1}=\frac{\gamma \beta p}{(1-\beta)(1-p)(1-\rho \gamma)} \Pi_{E+1}(1)+\frac{\gamma \rho}{1-\rho \gamma} z+\frac{\rho \gamma-(d \gamma)^{T}}{1-\rho \gamma} b+ \\
\frac{1-\gamma}{1-\rho \gamma}\left[(d \gamma)^{T} U_{E-10}++\frac{(1-p)(1-\rho \gamma)+\beta p}{1-p(1-\beta)} \sum_{k=0}^{T-1}(d \gamma)^{k} U_{E-1 T-(k+1)}\right] .
\end{gathered}
$$

Inserting (A51) into (A47) the statement follows by virtue of (A39) and (A40).

6. From (A47) and (A48) we can deduce that

$$
U_{E T}-U_{E T-j}=d \gamma\left[U_{E T-1}-U_{E T-(j+1)}\right]+d(1-\gamma)\left[U_{E-1 T-1}-U_{E-1 T-(j+1)}\right] .
$$

Solving this difference equation we arrive at:

(A53) $U_{E T}-U_{E T-j}=(d \gamma)^{m}\left[U_{E T-m}-U_{E 0}\right]+d(1-\gamma) \sum_{k=1}^{m}(d \gamma)^{k-1}\left[U_{E-1 T-k}-U_{E-1 T-(j+k)}\right]$,

where $m=T-j$.

For $U_{E T-m}-U_{E 0}$ we obtain from (A48), (A50) and (A45):

(A54) $U_{E T-m}-U_{E 0}=(d \gamma)^{T-(m+1)}\left[U_{E 1}-U_{E 0}\right]+d b \sum_{g=1}^{T-(m+1)}(d \gamma)^{g-1}\left[1+(1-\gamma)^{T-(m+g)} \sum_{k=1}^{k}\right]$,

as we will prove by induction over $m$. For $m=1$, the following results from (A48), (A50) and (A45):

$$
U_{E T-1}-U_{E 0}=d \gamma\left[U_{E T-2}-U_{E 0}\right]+d b\left[1+(1-\gamma) \sum_{k=1}^{T-2} d^{k}\right] .
$$

From this equation, we obtain:

$$
U_{E T-m}-U_{E 0}=d \gamma\left[U_{E T-(m+1)}-U_{E 0}\right]+d b\left[1+(1-\gamma) \sum_{k=1}^{T-(m+1)} d^{k}\right] .
$$

The solution of this difference equation gives (A54).

From (A42), (A47) and (A50) we get: $U_{E 1}-U_{E 0}=d b$. Inserting this expression into (A54), considering $m=T-j$, we get:

$U_{E T-m}-U_{E 0}=b d\left(1-d^{j}\right) /(1-d)$. Using this equation in (A53) and rearranging terms gives the statement by virtue of (A42), from which: $U_{E-1 T-k}-U_{E-1 T-(j+k)}=b d^{T-(j+k-1)} \sum_{n=0}^{j-1} d^{n}$. 


\section{Recently published}

No.

1/2004 Bauer, T. K. Bender, S.

Bonin, $\mathrm{H}$.

2/2004 Achatz, J.

Gartner, $\mathrm{H}$. Glück, T.

3/2004 Andrews, M. Schank, T. Upward, R.

4/2004 Brixy, U. Kohaut, S. Schnabel, C.

5/2004 Kölling, A. Rässler, S.

6/2004 Stephan, G. Gerlach, K.

7/2004 Gartner, H. Stephan, G.

$\underline{1 / 2005}$ Blien, U. Suedekum, J.

2/2005 Brixy, U. Kohaut, S. Schnabel, C.

3/2005 Lechner, M. Miquel, R. Wunsch, C.

4/2005 Hinz, T. Gartner, $\mathrm{H}$.

5/2005 Gartner, H. Rässler, S.

6/2005 Alda, $\mathrm{H}$. Bender, S. Gartner, $\mathrm{H}$.

7/2005 Haas, A. Rothe, $T$.

8/2005 Caliendo, M. Hujer, R. Thomsen, S. L.

9/2005 Gerlach, K. Stephan, G.

10/2005 Gerlach, K. Stephan, G.
Title

Date

Dismissal protection and worker flows in small establishments

$7 / 04$

Bonus oder Bias? : Mechanismen geschlechtsspezifischer

$7 / 04$

Entlohnung

published (revised) in: Kölner Zeitschrift für Soziologie und Sozialpsychologie 57 (2005), S. 466-493

Practical estimation methods for linked employer-employee data

Do newly founded firms pay lower wages? First evidence from Germany

$9 / 04$

Editing and multiply imputing German establishment panel

$10 / 04$

data to estimate stochastic production frontier models published in: Zeitschrift für ArbeitsmarktForschung 37 (2004), S. 306-318

Collective contracts, wages and wage dispersion in a multilevel model

How collective contracts and works councils reduce the gender wage gap

Local economic structure and industry development in Germany, 1993-2001

How fast do newly founded firms mature? : empirical analyses on job quality in start-ups published in: Michael Fritsch, Jürgen Schmude (Ed.): Entrepreneurship in the region, New York et al., 2006, S. 95-112

Long-run effects of public sector sponsored training in West Germany

Lohnunterschiede zwischen Frauen und Männern in Branchen, Berufen und Betrieben published as: Geschlechtsspezifische Lohnunterschiede in Branchen, Berufen und Betrieben. In: Zeitschrift für Soziologie 34 (2005), S. 22-39

Analyzing the changing gender wage gap based on multiply imputed right censored wages

The linked employer-employee dataset of the IAB (LIAB) published (shortened) as: The linked employer-employee dataset created from the IAB establishment panel and the process-produced data of the IAB (LIAB). In: Schmollers Jahrbuch. Zeitschrift für Wirtschafts- und Sozialwissenschaften 125 (2005), S. 327-336

Labour market dynamics from a regional perspective : the multi-account system

Identifying effect heterogeneity to improve the efficiency of job creation schemes in Germany

Wage distributions by wage-setting regime

Individual tenure and collective contracts 
$11 / 2005$

Blien, U.

Hirschenauer, $\mathrm{F}$.

$\underline{12 / 2005}$ Alda, $\mathrm{H}$.

Allaart, $P$.

Bellmann, $\mathrm{L}$.

13/2005 Caliendo, M.

Hujer, R.

Thomsen, S. L.

14/2005 Lechner, M. Miquel, R.

Wunsch, C.

15/2005 Jensen, U.

Rässler, S.

16/2005 Schnabel, C Zagelmeyer, S. Kohaut, S.

$\underline{17 / 2005}$ Koch, S. Stephan, G. Walwei, U.

18/2005 Alda, $\mathrm{H}$. Bellmann, L. Gartner, $\mathrm{H}$.

19/2005 Eichhorst, W. Konle-Seidl, R.

20/2005 Gerlach, K. Stephan, G.

21/2005 Fitzenberger, B. Speckesser, S.

22/2005 Ludsteck, J. Jacobebbinghaus, $P$.

1/2006 Gerlach, K.

Levine, D.

Stephan, G.

Struck, O.

2/2006 Ludsteck, J.

3/2006 Gaggermeier, C.

4/2006 Binder, J. Schwengler, B.

5/2006 Brixy, U. Grotz, R.

6/2006 Blien, U. Sanner, $\mathrm{H}$.

7/2006 Stephan, G. Rässler, S. Schewe, T.

8/2006 Gash, V. Mertens, A. Romeu Gordo, L.

9/2006 Romeu Gordo, L.
Formula allocation : the regional allocation of budgetary funds for measures of active labour market policy in Germany

Churning and institutions : Dutch and German establishments compared with micro-level data

Individual employment effects of job creation schemes in Germany with respect to sectoral heterogeneity

The curse and blessing of training the unemployed in a changing economy : the case of East Germany after unification

Where have all the data gone? : stochastic production frontiers with multiply imputed German establishment data

Collective bargaining structure and its determinants : an empirical analysis with British and German establishment data

Workfare: Möglichkeiten und Grenzen

published in: Zeitschrift für ArbeitsmarktForschung 38 (2005), S. 419-440

Wage structure and labour mobility in the West German private sector 1993-2000

The interaction of labor market regulation and labor market policies in welfare state reform

Tarifverträge und betriebliche Entlohnungsstrukturen

Employment effects of the provision of specific professional skills and techniques in Germany

Strike activity and centralisation in wage setting

$12 / 05$

$1 / 06$

America with Germany

Employment effects of centralization in wage setting in a median voter model

Pension and children : Pareto improvement with heterogeneous preferences

Korrekturverfahren zur Berechnung der Einkommen über der Beitragsbemessungsgrenze

Regional patterns and determinants of new firm formation and survival in western Germany

Structural change and regional employment dynamics

Wirkungsanalyse in der Bundesagentur für Arbeit : Konzeption, Datenbasis und ausgewählte Befunde

Are fixed-term jobs bad for your health? : a comparison of

West-Germany and Spain

Compression of morbidity and the labor supply of older people

Letzte Aktualisierung: 31.5.2006, 38 Einträge 


\section{Impressum}

IABDiscussionPaper

No. 10 / 2006

\section{Herausgeber}

Institut für Arbeitsmarkt- und Berufsforschung der Bundesagentur für Arbeit

Weddigenstr. 20-22

D-90478 Nürnberg

\section{Redaktion}

Regina Stoll, Jutta Palm-Nowak

Technische Herstellung Jutta Sebald

\section{Rechte}

Nachdruck - auch auszugsweise - nur mit Genehmigung des IAB gestattet

\section{Bezugsmöglichkeit}

Volltext-Download dieses DiscussionPaper

unter:

http://doku.iab.de/discussionpapers/2006/dp1006.pdf

IAB im Internet

http://www.iab.de

Rückfragen zum Inhalt an

Elke J. Jahn, Tel. 0911/179-5183, oder E-Mail: elke.jahn@iab.de 